\title{
Scale effect study on the modulus of subgrade reaction of geogrid-reinforced soil
}

\author{
Hussein Ahmad $^{1}$ (1) $\cdot$ Ahmad Mahboubi $^{1} \cdot$ Ali Noorzad $^{1}$
}

Received: 3 November 2019 / Accepted: 31 January 2020 / Published online: 12 February 2020

(c) Springer Nature Switzerland AG 2020

\begin{abstract}
Both experimental and numerical investigations conducted on strip footing laying down over the geogrid reinforced fine sand bed. Firstly, an evaluation of the significance of geogrid reinforcement to enhance the soil's strength is required to carry out a series of a small-scale model of reinforced and unreinforced soil beneath static loading. Next, the series of the large-scale numerical analyses were implemented to define the soil bed reaction modulus and bearing capacity ratio of reinforced sand soil in plane strain conditions. The Mohr-Coulomb soil constitutive model was used to represent the fine sandy soil and the linear elastic tension model was utilized for modeled geogrid reinforcement elements. One of the most beneficial outcomes in the unreinforced soil case, the ultimate bearing capacity progress occurs by developing the width of the strip footing. Then in reinforcing case, an uppermost geogrid layer's depth under the footing and the fittest spacing between the reinforcing layers are not affected by the wide ranges of the footing widths. Their optimum values are similar to the works of literature $(u / B=0.3$ and $h / B=0.4)$, but they are affected by soil friction angles. Finally, the achievement of this study indicates that the coefficient of soil reaction is associated with a nonlinear behavior with the relative ratio of tensile stiffness of the geogrid to the elasticity modulus of soil and enhanced by increased the number of geogrid layers. The influence of geogrid length on subgrade modulus is negligible and only the effective depth is affected it. The value of reaction modulus decreases when both the footing width and settlement increase. A simple new method is proposed to determine an approximate value of subgrade reaction modulus in reinforced soils.
\end{abstract}

Keywords Physical modeling · Scale effect · Bearing capacity · Fine sand · Geogrid · Subgrade reaction modulus

\section{Introduction}

Shallow foundations are frequently built on grounds with low resistance, ensuing in the inability of the structure, either to the weak strength of soil or to increased settlements of footing. One of the approaches scientifically proposed to solve this problem is to improve soil resistance using a reinforcement technique that helps to increase soil stability and to reduce the stresses transferred from the base to the soil mass.

Improving the resistance of weak soil using geosynthetic material is a successful way to support the stability of many geotechnical engineering structures such as dams, road construction, excavations, slopes, and foundations. Geogrid is one of the high-resistance of geosynthetic material that included within the compacted soil mass for increasing their bearing capacity and reducing settlement. Thus, to comprehend the reaction of the geogrid reinforced-soil zone, the investigators were conducting the small-scale model tests. The important inquiry is how to approximate the performance and response of the geogrid reinforced soil in the experimental model using the diminished scale in comparison with the large scale

Hussein Ahmad, Houssein.ah@gmail.com; Ahmad Mahboubi, A_mahboubi@sbu.ac.ir; Ali Noorzad, A_Noorzad@sbu.ac.ir| ${ }^{1}$ Faculty of Civil, Water and Environmental Engineering, Shahid Beheshti University, Tehran, Iran. 
prototype? Numerous researchers focused on this problem in geotechnical studies being the affect scale.

\section{Background}

The subject of scale effect has been extremely crucial to the comprehension of the unreinforced and reinforced soil behavior that turned up beneath the shallow foundations [1-12]. DeBeer [1] was concluded that bearing capacity is not increased linearly based on the width of a footing. These signify that the aspects of scale effect are slightly due to the nonlinear curvature of the soil behavior at failure. It depended on the internal friction angle values, the relative density and means normal effective stress. Therefore, the denser soil the most curvature and then the loose soil the failure envelope is linear $[10,11]$. Toyosawa et al. [12] reported that three factors are responsible for the scale impacts: the mean stress level of contact surface, grain size distribution and the footing embedment depth. This essential percentage ratio of $\left(B / d_{50} \%\right.$ where $B$ shows footing width and $d_{50}$ represents the mean grain size of soil) does not affect the results if their values are greater than $50-100$ (75 on average) to avoid the particle size reaction $[11,13]$. Cerato and Lutenegger [4] have been concluding that developing the various ranges of footing width for different kinds of shallow foundations is leads to reduce in the "the bearing capacity factor, $\mathrm{N} \gamma$,. Also, it is broadly understood that the scale footing size does not affect the behavior of the fine-grained soils as it is for coarse-grained soils. The same outcomes reported for numerous values of internal friction angles and he means principal stresses [5]. Many researchers have confirmed that reducing the size effect phenomena on the footing and aperture geogrid dimension produces an essential duty in improving the reinforced soil mechanical response, particularly in the event of laboratory research on a smallscale model. Das and Omar [3] decided that the tiniest wideness of the footing to be implemented in the laboratory on a small-scale model should be greater than $140 \mathrm{~mm}$. Consequently, the load applied is not considered central and therefore different results obtained by comparison with the standard model. Fakher and Jones [14] pointed out that not bringing into account the scale effect in reinforced soils will lead to unacceptable outcomes and thus the mechanism of reinforcement is not assessed in actual conditions. They affirmed that, by using the dimensional analysis, the geogrid reinforcement tensile strength and stiffness that used in the small-scale laboratory model are smaller than those employed in the prototype model by $\mathrm{N}$ and $\mathrm{N}^{2}$ times, respectively, where $\mathrm{N}$ is the scale employed in the laboratory model. The large-scale field test was performed to assess the performance of the inclusion grid-anchor system in granular soils underneath square footing and it is compared with an experimental study Mosallanezhad et al. [7]. They concluded the square footing widths did not affect the BCR values. The relationship between unreinforced soil bearing capacity and wide range of the footing width is linear, however, the reinforced soil carrying capacity behaves as non-linear correlation. The behavior of geogrid-reinforced soil with different widths strip footing by conducting cyclic loading is investigated [8]. The discoveries notified strength of the different sandy soils were improved because of the increasing of the essential percentage ratio $\left(B / d_{50} \%\right)$. It was realized these results that the medium grain size fine sandy soil must be reached to be 0.25 of the geogrid apertures and 0.05 of the footing widths [8]. The footing width needs to be chosen at least 5 times of the geogrids aperture [8]. Sameh Abu El-Soud et al. [9] have been studying the enhancement of the resolution characteristics and bearing capacity of a rigid shallow foundation on fine dune sands utilizing geogrid reinforcement to show acceptable performance. The testing plan includes 24 trials on the loading plate on a steel bar with a different widths (B): 75, 100 and $120 \mathrm{~mm}$, which is posted on the reference unarmed sand to find the ratio of endurance (BCR) to be held. It was possible to monitor adding the ground's mobilized bearing capacity compared to the unreinforced dune sand bed. The higher BCR appears for smaller footing in their subject area compared to the larger footing in the same field; thus, the reinforced soil method was effective for smaller strip footings. A few studies of numerical analysis have done on the "scale effect" of unreinforced and reinforced soil foundation. Chen [6] carried out a series of numerical analysis tests. Regarding the numerical analysis, the footing width impact was essentially concerned with the "reinforced ratio" of their reinforced soil region [6]. The "reinforced ratio" is relative to the geogrid reinforcement's tensile modulus and contrariwise proportionate to the total depth of geogrid reinforcement when the same soil is utilized [6]. Afterward, this "reinforced ratio" also integrates the impacts of the geogrid layer number, embedment depth, etc. Zhu et al. [15] considered the numerical analysis accompanied by the scale effect experimental tests to assess the bearing capacity improvement of two types of footings. They were discovered that the greater footing widths, the greater bearing capacity. Hence, "the coefficient bearing capacity $\mathrm{N}^{\prime \prime}$ "in granular soils decreases with increasing proportion. Although, most studies focused on the identification of a reinforced soil bearing capacity ratio, these researchers did not address the foundation reaction modulus. The concept of the reaction coefficient was suggested by Winkler. Hence, the researches of Tarzaghi [16], Bowles [17] and Selvadurai [18] have imposed experimental laboratory relationships to set the value of this 
coefficient. In the current engineering studies and depending on the geometric point of opinion, this factor has been conceived to act as a key character in the issues of the interaction soil-geogrid. It can be calculated from the settlement-applied pressure curve response under the plate load test laboratory. At this time, all the works concentrated on measuring the bearing capacity ratio, but a few of these researches were considered the magnitude of the soil bed reaction modulus in reinforced soil. In the current work, small-scale tests were applied for simulating the strip footing resting on the fine-grained soil exposed to static loading. The effects of the applied stress-settlement response curve compare with an FE numerical model by conducting the program PLAXIS version 8.2 [19]. Alamshahi and Hataf [20] were carried out a series of finite element analyses along the bearing capability of the rigid strip footing constructed on a sand slope. A numerical investigation related to the optimal burial depth of the reinforcement within sand formations was done by Aria et al. [21]. Boushehrian and Hataf [22] carried out both experimental and numerical model tests on circular and ring shallow foundation elements to inspect the bearing capacity of geosynthetic-reinforced sand. Basudhar et al. [23] were conducted circular footings resting on geotextile-reinforced sand bed. They anticipate the load-settlement characteristics using both analytical and numerical modeling then those compared with a physical laboratory model output. El Sawwaf [24] examined the behavior of the strip footing on geogrid-reinforced sand over a soft clay slope. The possible aids by using replacement with a reinforced sand layer made adjacent to a slope crest was considered. A range of two-dimensional plain strain finite element analyses (FEA - using PLAXIS — was done along a physical slope model. Chao [25] ran out the improving bearing capacity of shallow foundations on weak soils utilizing geosynthetic reinforcing technique. Zidan [26] was conducted the numerical study to determine the behavior of circular footings on geogrid-Reinforced sand under static and dynamic Loading. Yu [27] was discussed the influence on choice of commercial software programs (FLAC and PLAXIS) on interface models of reinforced soil-structure interactions. Most of these studies concentrated on assessing the impact of geosynthetic reinforcement on increasing the soil bearing capacity and did not address the discussion of the coefficient of the reinforced soil reaction. In the current study, the numerical analysis aid in comprehending the behavior of the geogrid-fine sand system under static loading. The original purpose of the aforementioned performance is to identify the measurable relationship between the bed reaction modulus and the mechanical characteristics ofthe geogrid-reinforced soil. Based on the analytical methods proposed by several researchers, it should be confirmed the results of these numerical analyses for the reaction modulus that including the statistical analysis of the conclusions.

\section{Properties of materials used}

In order to conduct the small-scale model in the laboratory, it is necessary to prepare laboratory materials for this experimental study and the fabrics are characterized as follows:

\subsection{Soil}

The soil utilized in the laboratory testing program is finegrained sandy soil with code 151, which was brought from the mountainous area of Firozkoh, northeast of Iran. The grain size analysis was carried out based on the ASTM D422 standard for soil classification using a series of sieves with graduated measurements such as N20, N30, N40, N50, N70, N100, N200, Pan, and the laboratory results were sequentially $c_{C}=1.11, \mathrm{cu}=1.90$, (mean particle size) $\mathrm{d}_{50}=0.34 \mathrm{~mm}$, (impact particle size) $d_{10}=0.2 \mathrm{~mm}, d_{\max }=0.425 \mathrm{~mm}, d_{\min }=0.01 \mathrm{~mm}$. The Unified Soil Classification System (USCS) classified this material as sand poor-graded soil (SP) as shown in Table 1 and Fig. 1. The dry bulk density was determined in the laboratory according to ASTM D2049 by using a half-inch funnels and the standard Proctor experiment with a diameter of $151.6 \mathrm{~mm}$ and the height of the mold is $107.0 \mathrm{~mm}$. As a result, the value of the dry volume density is $\gamma_{\mathrm{dmin}}=14.09 \mathrm{kN} / \mathrm{m}^{3}$. In the same mold, the vibrator table test was carried out to determine the maximum dry density, their value is $\gamma_{d \max }=16.61 \mathrm{kN} / \mathrm{m}^{3}$. The specific gravity is $\mathrm{Gs}=2.68$. Various studies have shown that the size of the sample does not affect significantly the friction parameters obtained in the test $[2,11,15,18]$, these works recommend that a ratio between mean particle size to the length of the box must be in the range of 50-300, Infante [28]. A series of nine direct shear small box test were conducted to compute the mechanical

Table 1 The mechanical and physical features of fine sand soil

\begin{tabular}{lll}
\hline $\begin{array}{l}\text { Relative density } \\
\text { ASTM D2049 }\end{array}$ & $\begin{array}{l}\text { Direct shear test } \\
\text { ASTM D5321 }\end{array}$ & $\begin{array}{l}\text { Sieve analysis ASTM } \\
\text { D422 }\end{array}$ \\
\hline$\Upsilon_{\mathrm{dmax}}=16.61 \mathrm{kN} / \mathrm{m3}$ & $C_{\text {soil }}=15 \mathrm{kPa}$ & $\mathrm{C}_{\mathrm{u}}=1.90$ \\
$\Upsilon_{\mathrm{dmin}}=14.09 \mathrm{kN} / \mathrm{m3}$ & $\phi_{\text {residual }}=29.33^{\circ}$ & $\mathrm{C}_{\mathrm{c}}=1.11$ \\
$\mathrm{e}_{\max }=0.866$ & $\phi_{\text {peak }}=36.5^{\circ}$ & $\mathrm{d}_{50}=0.34 \mathrm{~mm}$ \\
$\mathrm{e}_{\min }=0.583$ & $C_{\mathrm{i}, \text { residual }}=13.45 \mathrm{kPa}$ & $\mathrm{d}_{10}=0.20 \mathrm{~mm}$ \\
$\mathrm{e}_{(\Upsilon=15)}=0.753$ & $\phi_{\mathrm{i} \text {, residual }}=38.37^{\circ}$ & $\mathrm{d}_{30}=0.29 \mathrm{~mm}$ \\
$\Upsilon=15 \mathrm{kN} / \mathrm{m}^{3}$ & $\psi=6.5^{\circ}$ & $\mathrm{d}_{60}=0.38 \mathrm{~mm}$ \\
$D_{\mathrm{r}}=40 \%$ & At $D_{\mathrm{r}}=40 \%$ & $d_{\max }=0.425 \mathrm{~mm}$ \\
& & $d_{\min }=0.01 \mathrm{~mm}$ \\
& & $S P($ USCS)
\end{tabular}




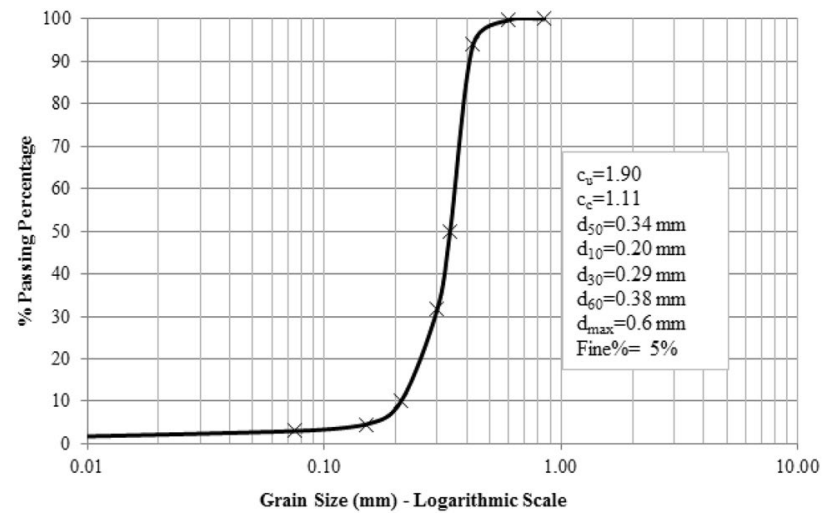

Fig. 1 Particle size distribution analysis

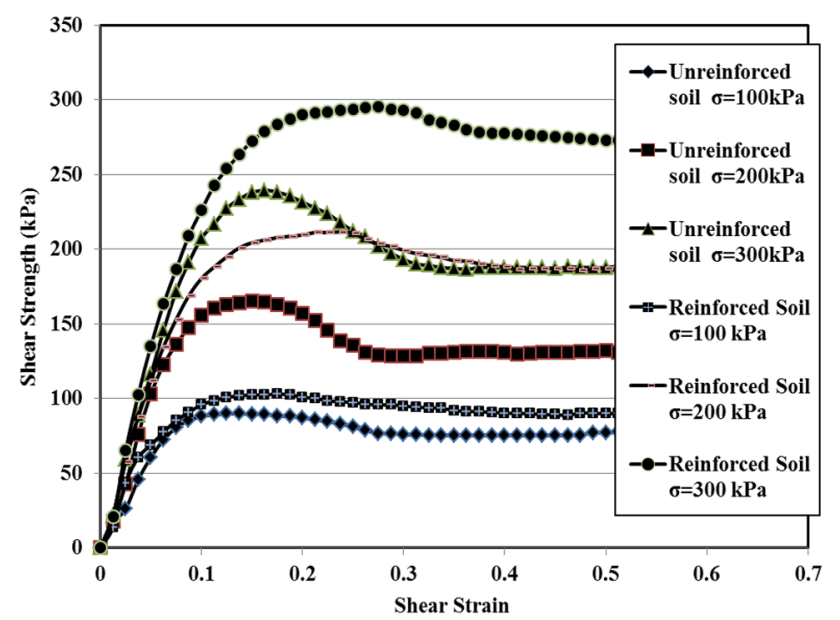

Fig. 2 Direct shear test results for firozkoh soil

properties of fine sandy soil and geogrid-sand interaction coefficient. The geogreid specimens were positioned perpendicular to the failure plane in order to determine the behavior of soil-geogrid system when the shear force acts normal to the reinforcing layer, Athanasopoulos [29] and Infante [28]. The soil's friction angle at residual, the soil friction angle at peak, the dilation angle and cohesion of dry sandy soil obtained from the direct shear test ( $60 \mathrm{~mm} \times 60 \mathrm{~mm}$ ) according to (ASTM D5321) at relative density $40 \%$ are $29.33^{\circ}, 36.5^{\circ}, 6.5^{\circ}$ and $15 \mathrm{kPa}$, respectively, as depicted in Figs. 2 and 3. The oedometric elasticity modulus obtained from the one-dimensional test in a dry case as indirect value is $\mathrm{E}_{\text {oed }}=28 \mathrm{MPa}$.

Figure 2 indicates an increase in the shear modulus of the soil by the inclusion of a geogrid element into the sandy soil. As a result, both the angle of internal friction and the apparent cohesion increase.

The relative density and void ratio are calculated as, Das BM [30]:

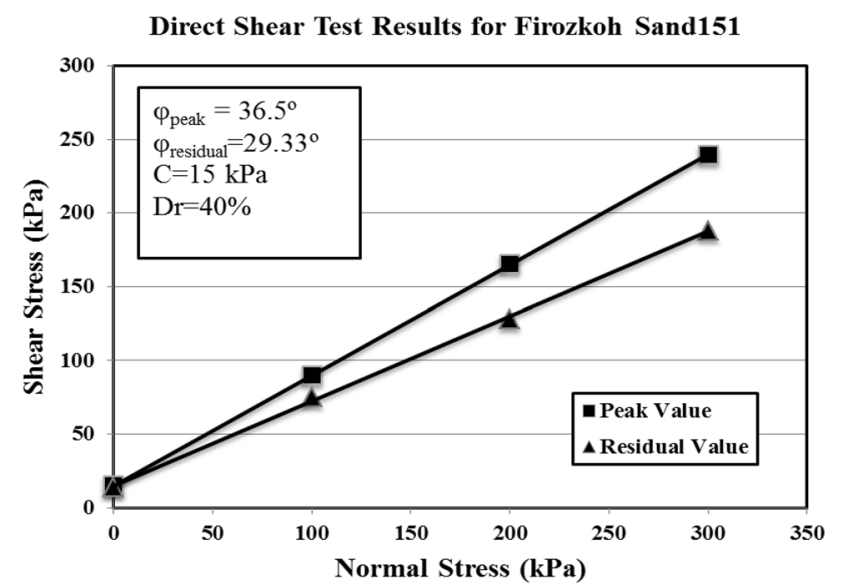

Fig. 3 Mohr-Columb envelope curve for firozkoh soil

Table 2 The physical characteristics of geogrid

\begin{tabular}{ll}
\hline Physical characteristics of Geogrid CE161 \\
\hline HDPE & Polymer (Polyethylene) \\
\hline $10 \times 10$ & Mesh aperture size $(\mathrm{mm})$ \\
3.3 & Mesh thickness $(\mathrm{mm})$ \\
700 & Structural weight $(\mathrm{gr} / \mathrm{m} 2)$ \\
Mechanical Properties of Geogrid CE161 \\
6.1 & Tensile strength, max load $(\mathrm{kN} / \mathrm{m})$ \\
51.7 & Extension at max load $(\%)$ \\
2.9 & Load at 10\% extension $(\mathrm{kN} / \mathrm{m})$ \\
1.06 & Tensile strength at strain $2 \%(\mathrm{kN} / \mathrm{m})$ \\
1.71 & Tensile strength at strain $5 \%(\mathrm{kN} / \mathrm{m})$ \\
\hline
\end{tabular}

$D_{r}=\frac{\left[\frac{1}{\gamma_{d(\text { min })}}\right]-\left[\frac{1}{\gamma_{d}}\right]}{\left[\frac{1}{\gamma_{d(\min )}}\right]-\left[\frac{1}{\gamma_{d(\max )}}\right]}=\frac{\gamma_{d}-\gamma_{d(\min )}}{\gamma_{d(\max )}-\gamma_{d(\min )}} \times \frac{\gamma_{d(\max )}}{\gamma_{d}}$

$e=\frac{G_{s} \cdot \gamma_{w}}{\gamma_{d}}-1$

\subsection{Reinforcement element}

The geogrid CE161 utilized in this study was created by an Iranian company (Mesh Iran). This kind of geogrid possesses the thickness of $3.3 \mathrm{~mm}$ and a $10 \times 10 \mathrm{~mm}$ aperture size with a mass of $0.700 \mathrm{~kg} / \mathrm{m} 2$. The final tensile strength was measured at about $6.1 \mathrm{kN} / \mathrm{m}$. This kind of geogrid has the similar tensile strength in all directions. The material features of the reinforcement are also provided in Table 2, presented by the manufacturers. 


\subsection{Model footing}

In this study, a strip element is made of steel used for modeling the footing in plane strain condition. The thickness of footing is $20 \mathrm{~mm}$ such that it can be considered as a solid element and does not subject to scale effect. The footing width is $100 \mathrm{~mm}$, which is 5 times smaller than the length of the box model. The length of footing is selected to $440 \mathrm{~mm}$ that rests in the same direction of the width of the laboratory model box and less than $10 \mathrm{~mm}$ of it. It is using a coarse sand adhesive layer with epoxy glue on the bottom surface of the footing to ensure a uniform roughness in all tests. The static applied loading is at the center of the strip footing, return to Fig. $5 b$.

\section{The test setup and experimental procedure}

The laboratory small-scale model is a rectangular box made of steel and it has an internal dimension $450 \mathrm{~mm}$, $1100 \mathrm{~mm}$, and $1600 \mathrm{~mm}$ in width, height, and length, respectively. The conditions of the model study were chosen according to the plane strain problem. The relative dimensions of the model length to the footing width is 16 , which is sufficient to prevent the failure surfaces from interfering with the lateral dimensions of the box study. The height of soil mass in the model to be up to $1000 \mathrm{~mm}$ $(H / B=10>3)$. The box width is equivalent to the width of the footing and the footing length was reduced by $5 \mathrm{~mm}$ from each side of its to avoid contact footing with the wall of the sandbox.

A loading system for the load application is a pneumatic cylinder connected to an air compressor providing about 10 bar air pressure. This system is capable of securing a regular periodic load in accordance with the pressure conditions applied to the soil sample. The jack loading is equivalent to 5 tons, sufficient to transport the soil load to

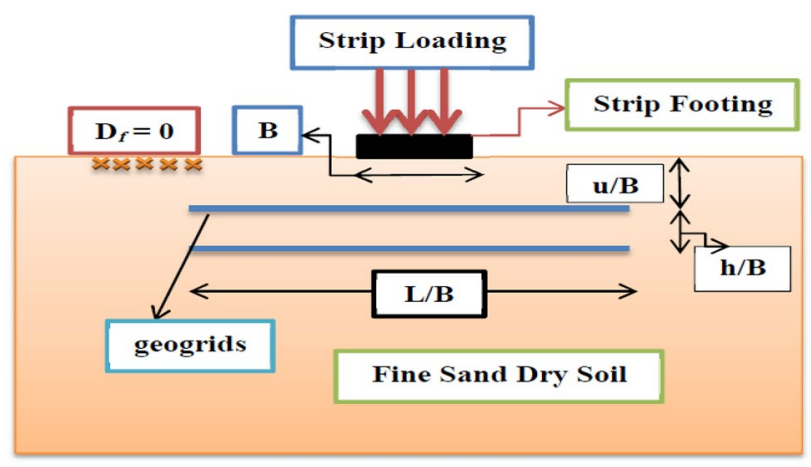

Fig. 4 The schematic view of the experimental apparatus obtain the marginal tolerance of the soil in all experiments. The load cell has S-shape and it helps to magnitude the applied force. Two linear variable differential transformer (LVDT) was utilized for determining the footing settlement. Both (LVDTs) made in Turkey (OPKON Company), and the compressor made in Italy. The schematic view of the experimental apparatus is represented in Fig. 4. To prepare the test samples, the technique of rain sandy soil was used to obtain a regular placement of soil in the sandbox and proportional to the required relative density [31]. The rainfall height and the sand particle's speed have been calibrated through several trials in a special steel cup to obtain the appropriate values of relative density. The tamper was used in a number of suitable cycles to obtain the appropriate unit weight of soil. The unit weight of fine sand and relative densities are $15 \mathrm{kN} / \mathrm{m}^{3}$ and $40 \%$, respectively. The schematic of this study is shown in Fig. $5 \mathrm{a}$.

\section{Numerical simulation}

Numerical modeling has become a requirement for simulating many complex technical issues. The finite element method is an effective numerical modeling technique that is widely applied in the domains of civil engineering in general and in geotechnical engineering in particular Zidan [26]. This analysis aimed at identifying the deformation of failure patterns and stress-strain performance of the reinforced soil system. Moreover, a decent technique is considered for observing the parametric study that is quantified in the plate load tests like the plate effect for using a large scale footing El Sawwaf [24]. The commercial engineering program in the finite element method was practiced to evaluate this work. PLAXIS 2D is a powerful finite element software package El Sawwaf [24]. Within this study, tracing on the benefits of "the finite element program", the behavior of reinforced soil underneath a strip footing can be analyzed to hold away the problem of scale issue. In this topic, strip footing modeling was simulated as a two-dimensional plane strain model. For simulating the soil-geogrid interaction in the model investigation, the interface element was utilized on both structures' sides, which enables for specifying a reduced wall friction in comparison with the soil friction (by basing on Coulomb friction law) [32]. The reinforcements are lean items with normal stiffness without bending stiffness able to only endure tensile forces and no compression [21-23]. The only reinforcement's substance feature is an elastic standard (axial) stiffness [24]. The primary stress condition was run first using the gravitational force caused by the soil weight in stages with the geogrid reinforcements in place [32]. The non-linear Mohr-Coulomb criterion was used for modelling the fine-grained sand as a result of its 


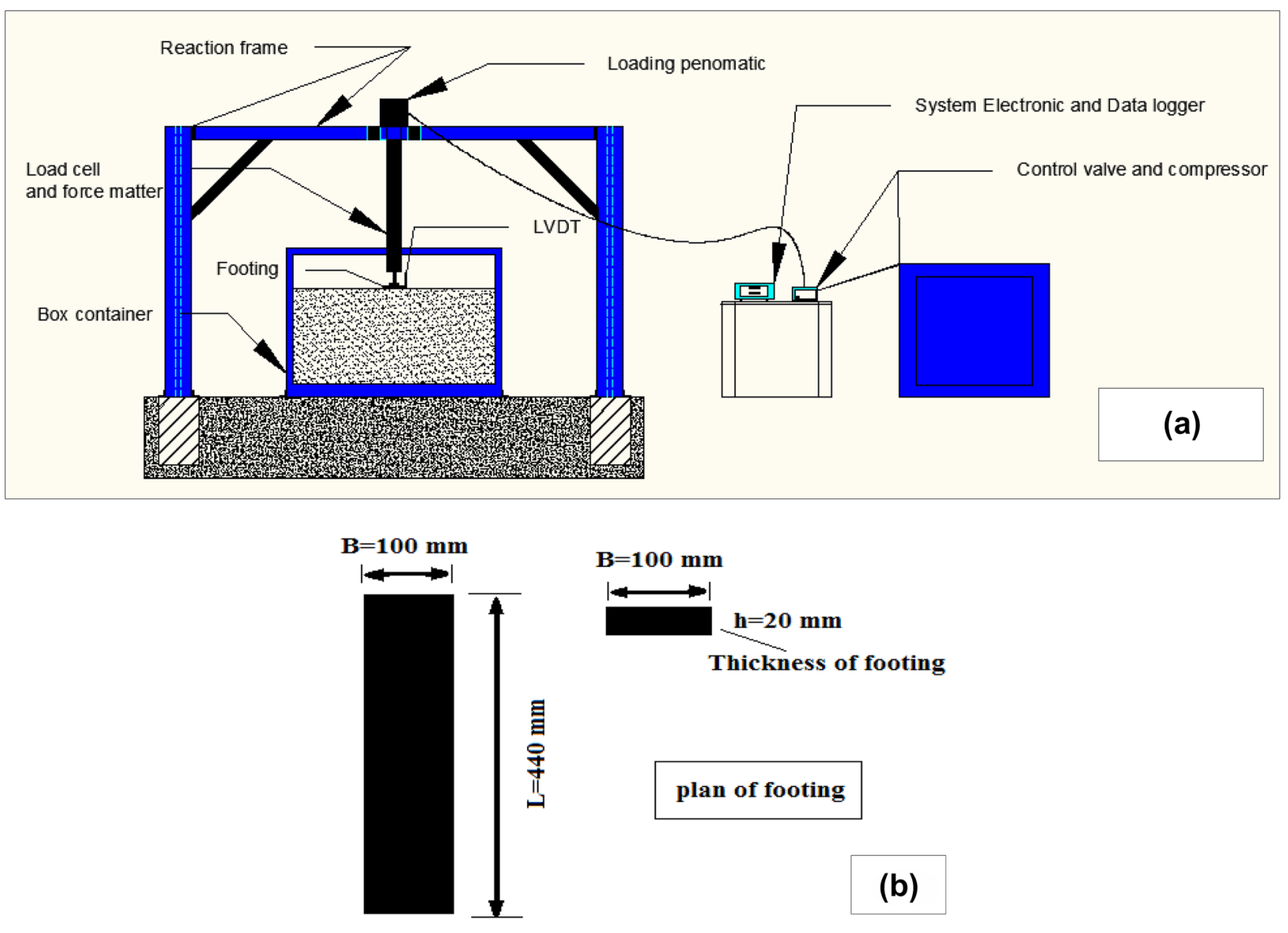

Fig. 5 a The view of the small-scale model study. $\mathbf{b}$ The plan view of strip footing

practical importance, simplicity, and the accessibility of required elements. The, a prearranged footing load was used in increases along with iterative analysis up to failure $[23,24,26]$. The boundary circumstances of the model constrained in the horizontal axis and were free vertically [32]. However, the bottom horizontal boundary is entirely fixed. The dry conditions carried out and the groundwater level omitted. The footing is modeled as a solid strip element so that the thickness of the footing is sufficient to prevent any bending in the direction of footing width [24]. Therefore, the applied pressure can be modeled as an equivalent settlement overall the footing width [19]. Recently here, the foundation depth is considered equal to zero $\left(D_{f}=0\right)$ and the base is modeled on the surface of the soil directly as used in the laboratory model. The initial condition of the reinforced and unreinforced soil was recognized by using the gravitational force in the first step of the analysis [19]. Then, an arranged footing load was used in increases along with iterative analysis up to failure [22-24]. The ultimate settlement of soil is considered the basis for evaluating the effectiveness of reinforcement and comparison with the case of unreinforced soil. The settlement as a prescribed load was applied and computed as follows:

$s=\frac{q_{s f}}{k_{s}}$

$\mathrm{S}$ : settlement of footing $(\mathrm{m})$.

$\mathrm{q}_{s f}:$ contact pressure beneath soil-footing surface $(\mathrm{kPa})$. $\mathrm{k}_{s}$ : the soil bed reaction modulus $\left(\mathrm{kN} / \mathrm{m}^{3}\right)$.

The following relationship to determine the reaction modulus value was proposed by Selvadurai [18]:

$\boldsymbol{k}_{\mathbf{s}}=\frac{\boldsymbol{E}}{\boldsymbol{H} \times(1-2 \vartheta) \times(\mathbf{1}+\boldsymbol{\vartheta})}$

where $\mathrm{H}$ shows the effective thickness of sand bed beneath footing $(\mathrm{H}=3 \mathrm{~B})$, $(\mathrm{E})$ and $(\mathrm{U})$ are the elasticity modulus of soil and Poisson's ratio, respectively. The selection of Poisson's ratio is especially simple when the Mohr-Coulomb model is used for gravity loading $[19,20,30-40]$. In this loading case Plaxis will generate a realistic ratio of 
$\mathrm{K}_{\mathrm{o}}$-value and there is a simple relationship between a Poisson's ratio and static coefficient in this model $\left(u=\frac{\boldsymbol{K}_{0}}{1+\boldsymbol{K}_{0}}\right)$. Hence, a Poisson's ratio $(U)$ is evaluated by matching $\mathrm{K}_{\mathrm{o}}$-value of Plaxis [32]. The fine-grained sandy soil was modeled utilizing 15-nodded triangular parameters and the behavior of this soil was simulated as nonlinear Mohr-Coulomb criterion [32]. Five main parameters are included in this constitutive model, i.e., elasticity modulus of soil (E) and Poisson's ratio (U); internal friction angle $(\varphi)$ and cohesion (c) and the dilation angle $\left(\psi=\varphi-30^{\circ}\right)$ [19]. In addition to the five mentioned model elements, the primary soil circumstances have a key role in soil deformation problems. The primary horizontal soil stresses should be created by choosing a proper $K_{0}$-value $\left(K_{0}=1-\sin \varphi\right)$. All these parameter studies are taken from laboratory standard tests and are shown in the Table 1. The Mohr-Coulomb elasticity modulus of soil computes according to the following relationship:

$$
\begin{aligned}
E_{\text {oed }} & =\frac{(1-\vartheta) \times E_{\text {ref }}}{(1-2 \vartheta) \times(1+\vartheta)} \stackrel{\text { inPlaxis }}{\Rightarrow} E_{\text {ref }} \\
& =\frac{(1-2 \vartheta) \times(1+\vartheta)}{(1-\vartheta) \times E_{\text {oed }}}=20.8 \mathrm{MPa}
\end{aligned}
$$

The geogrid's final tensile strength was determined at about $6.1 \mathrm{kN} / \mathrm{m}$. Based on the study of Abu-Farsakh et al. [33], in reinforced soil foundations the usual strain distribution of geogrid is less than $2 \%$, hence, the geogrid is supposed to be linear elastic. To determine the impact of effect, it can be used geogrid with the ultimate value of strain and tensile strength [6], i.e., the ultimate stiffness of geogrid is $\left(J_{\mathrm{u}}=\mathrm{T}_{\mathrm{u}} / \varepsilon_{\mathrm{u}}\right)$.

A series of numerical analyses were taken in assessing the effect of geometric dimensions on soil behavior and many engineering parameters. This was done by modifying the mesh sizes from coarse to fine according to sensitivity analysis as shown in Fig. 6a. During the Plaxis procedure, because of the value of applied stress of medium and soft mesh sizes are not much significant difference between them. The number of elements is 1020, as shown in Fig. 6c. To obtain exact results from the numerical analysis, the mesh size was refined under the strip footing region to a depth equivalent to twice the footing width [20]. Then it is a medium for the layer deeper. A characteristic arranged finite-element mesh of the numerical model is illustrated in Fig. $6 c$ for this study. Three principal model footing with different widths were considered and each of the footings was modeled with its own model as shown in Fig. 6b. In each model, the footing width (B), the depth of the first reinforcement layer $(\mathrm{u})$, the vertical distance between the reinforcement layers $(h)$, the length of the reinforcement $(L)$, the influence depth $\left(d_{r}\right)$ and the interface element were displayed in the previous figure.
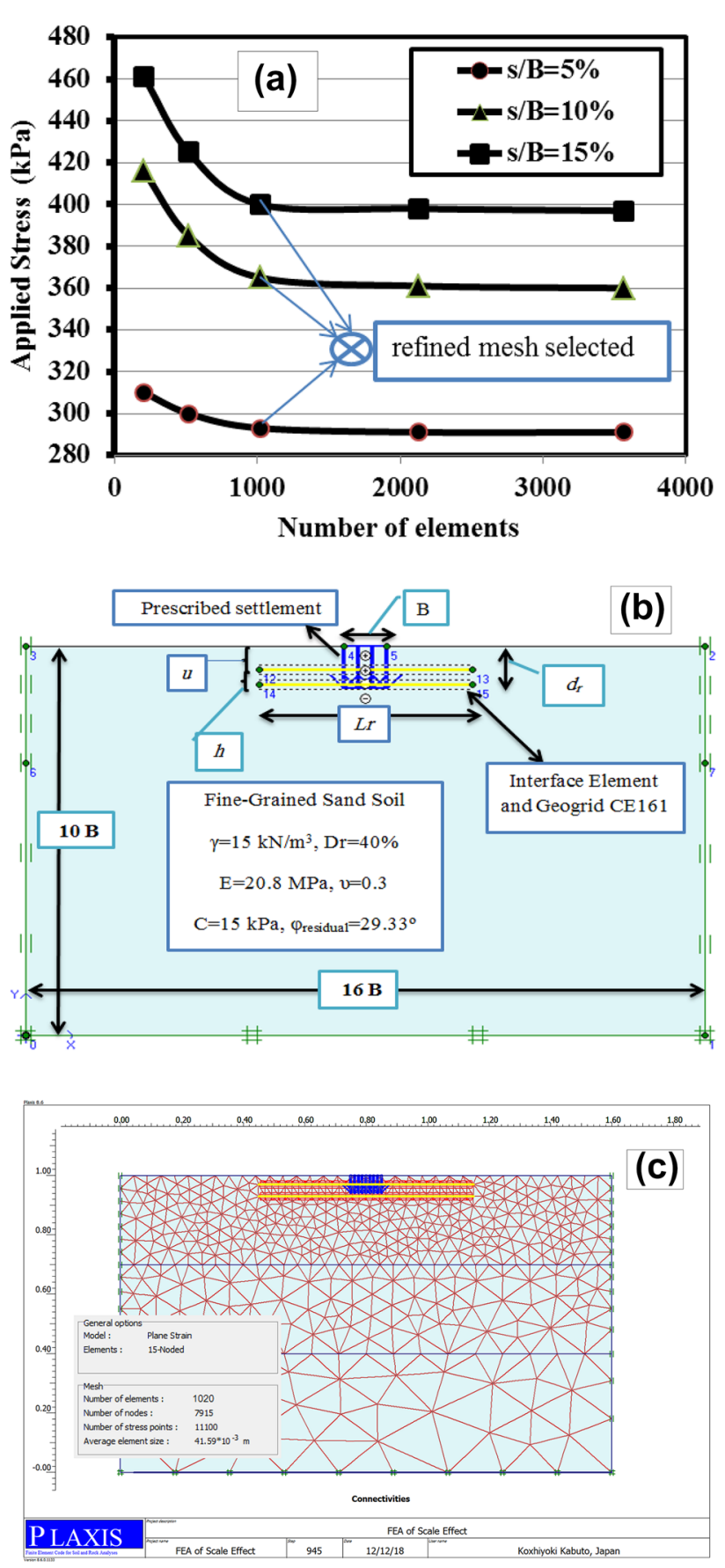

Fig. 6 a Sensitivity analysis of refined mesh, b FE modeling of geogrid-reinforced soil foundation and c Generated mesh size

The number of triangular elements is 1020 elements. The dimensionality of the model in the $Y$ and $X$ direction is $10 B$ and $16 \mathrm{~B}$, respectively (B shows the width of the footing). It is using 15-nodded triangular elements to simulate the soil and the geogrid was simulated with the 5 -node geogrid element.

Utilizing two contact surface pairs over and under the reinforcement layer, simulating the soil-reinforcement 
interaction was performed [32]. The constraint method is used by the PLAXIS contact interaction feature for modeling the interaction between a deformation item and a rigid item [19]. By this property, the master surface is provided by one surface definition and the slave surface is presented by the outer layer. After defining this contact pair, automatically a group of surface contact elements is created [32]. The simulation interaction includes two components: one tangential to the surfaces and the other normal to the surfaces [19]. The friction model of Coulomb was employed for modeling the shear interaction depending on the maximum acceptable frictional (shear) stress within an interface to the contact pressure within the contacting items [19]. The mechanical properties of interfaces are related to a soil layer's strength features [32]. Based on the soil features data, the "strength reduction factor" for interfaces $\left(R_{\text {inter }}\right)$ is determined as following rules [32]:

$\boldsymbol{c}_{\boldsymbol{i}}=\boldsymbol{R}_{\text {inter }} \cdot \boldsymbol{c}_{\text {soil }}$

$\tan \varphi_{i}=\boldsymbol{R}_{\text {inter }} \cdot \tan \varphi_{\text {soil }} \leq \tan \varphi_{\text {soil }}$

Six small direct shear tests having a dimension size of $60 \mathrm{~mm} \times 60 \mathrm{~mm} \times 25 \mathrm{~mm}$ was performed to define the properties of the interface surface and soil shear strength. The interface reduction is given based on the value of the residual internal friction angle of reinforced soil and his value is $\left(R_{\text {inter }}=0.79\right)[22,23,26]$, as shown in Fig. 7 . In the Plaxis for this case $\mathrm{R}_{\text {inter }}<1$ then $\psi_{i}=0^{\circ}$ [11].

It is worth mentioning that all the previous laboratory experiments were conducted in the dry state (the percentage of humidity is zero) to match the conditions of the laboratory model, which conducts all experiments without using water at all tests. As shown in Fig. 8, the numerical analysis program consists of three series: In the first series the soil is not reinforced, in the second and third series the

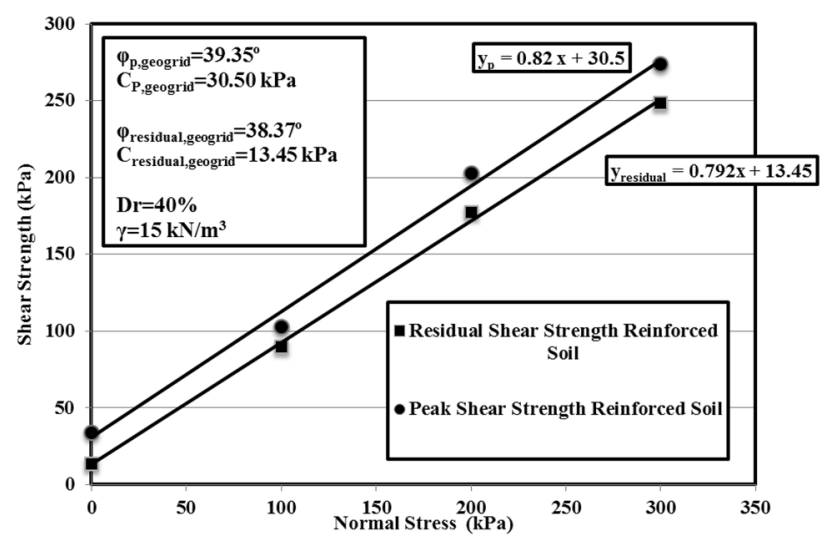

Fig. 7 Mohr-Coulomb envelope curve for firozkoh reinforced soil

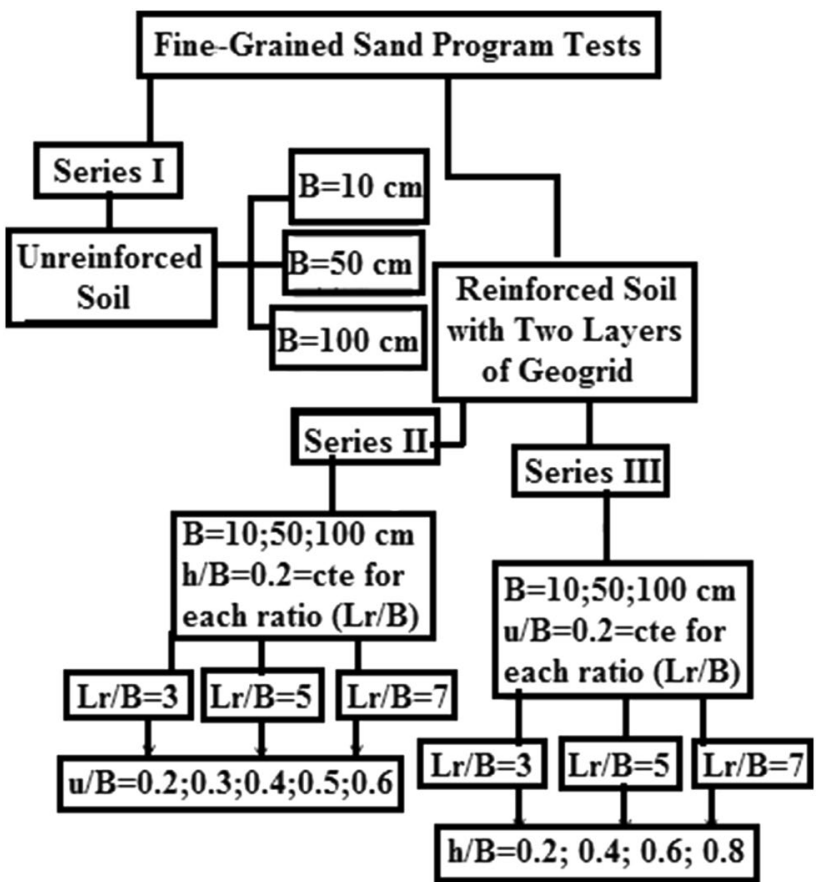

Fig. 8 FEM program testing

soil is reinforced with two geogrid layers and parameters that associated with these stages are changing.

In this research, the mechanical and physical features of the soil utilized in all models and scales are constant and have not changed, according to the measured scale based on the scaling law by Viswanadham and König [34]. Table 3 summarizes the factors of effect scale study and Table 4 give the magnitude adopted in the numerical analysis.

\section{Verification of the model}

A total of 20 laboratory experiments was conducted using the laboratory model test on a small-scale model to study the response of the strip footing on the fine sandy soil.

Table 3 The factors of the scale effect study [34]

\begin{tabular}{ll}
\hline Parameters & Scale factor \\
\hline Dimensions & $\mathrm{N}$ \\
Soil density & 1 \\
Applied pressure $(\mathrm{kPa})$ & $\mathrm{N}$ \\
Geosynthesis tensile strength & $\mathrm{N}^{2}$ \\
Geosynthesis stiffness modulus & $\mathrm{N}^{2}$ \\
Settlement, s & $\mathrm{N}$ \\
Friction angle, $\varphi^{\circ}$ & 1 \\
Cohession, $\mathrm{c}$ & 1 \\
Soil modulus & 1
\end{tabular}


Table 4 The values of factors in the different scales

\begin{tabular}{llll}
\hline Scale model & $\mathrm{N}=1$ & $\mathrm{~N}=5$ & $\mathrm{~N}=10$ \\
\hline Footing width $(\mathrm{m})$ & $0.1-0.2$ & $0.3-0.5$ & 1.00 \\
Applied pressure $(\mathrm{kPa})$ & 200 & 1000 & 2000 \\
Geogrid tensile strength $(\mathrm{kN} / \mathrm{m})$ & 6.1 & 152.5 & 610 \\
Stifness of geogrid $(\mathrm{kN} / \mathrm{m})$ & 11.8 & 295 & 1180 \\
Prescribed settlement $(\mathrm{m})$ & 0.02 & 0.1 & 0.2 \\
Width of model $(\mathrm{m})$ & 1.6 & 8 & 16 \\
Height of model $(\mathrm{m})$ & 1 & 5 & 10 \\
Friction angle, $\varphi^{\circ}$ & 29.33 & 29.33 & 29.33 \\
Cohession, $\mathrm{c}(\mathrm{kPa})$ & 15 & 16 & 15 \\
Soil modulus, E $(\mathrm{MPa})$ & 20.8 & 20.8 & 20.8 \\
\hline
\end{tabular}

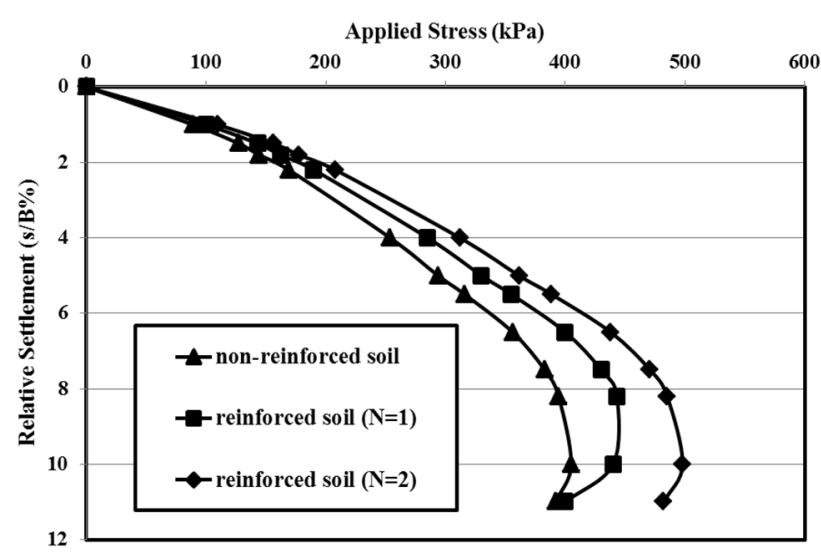

Fig. 9 Effect of geogrid inclusion on the sand response by plate width $(B=0.1 \mathrm{~m})$

In addition, some numerical analyses were conducted to study the scale effect on the behavior of geogrid-reinforced soil according to the plane strain conditions. "A non-dimensional factor $(B C R)$ " was employed to represent "the bearing capacity ratio" of the strip footing laying over reinforced soil [2-20, 30, 31, 33, 34]. This "enhancement factor" is determined as the ratio of applied stress on the geogrid reinforced soil $\left(\left(q_{u}\right)_{\text {reinforced }}\right)$ to the applied stress on non-reinforced soil $\left(\left(q_{u}\right)_{\text {non-reinforced }}\right)$ [20]. In this study, the applied stress will be depended on the value of the settlement equal to ten percent of the footing width (0.1 B) $[20,33,34]$, when the level of collapse is formed definitively. The vertical settlement of footing will be expressed in millimeter and the results curves will be drawn by the applied stress and relative settlement ( $\mathrm{s} / \mathrm{B} \%)$.

Figure 9 illustrates that the development of a geogrid layer leads to a $13 \%$ increase in soil tolerance and in the case of inclusion two geogrid layers, the endurance factor ratio increases to $28 \%$ compared with the unreinforced soil case at the same ratio of relative settlement $(\mathrm{s} / \mathrm{B}=10 \%)$.

To verify the numerical modeling, the final bearing capacity of the above series will be compared with the results of the experimental tests [24]. The result of applied pressurerelative settlement response was shown in Fig. 10. In this figure the numerical model calculations show a good match with the outcomes of the laboratory model. However, there is a slight difference between experimental and numerical results. This distinction can be ascribed to the characteristics of the soil, footing, and the geogrid reinforcement elements that are chosen and also due to the environmental conditions of plain strain in both the numerical and laboratory models Alamshahi and Hataf [20]. Then, to calibrate the results from both the laboratory and numerical analyses, the final bearing capacity of soil has been verified with four experimental equations according to Table 5 . There was a good correlation with the Vesic, Mayerhoff, and Hansen methods. It is worth to note that the bearing capacity finite element prediction is considerably smaller compared to the Terzaghi's bearing capacity. Various reasons may contribute in this difference, of which the most significant one is that in Terzaghi's equation the soil is assumed as a rigid-perfectly plastic substance failing abruptly by reaching the soil's bearing carrying [6]. However, in the existing finite element analysis the soil is assumed as a nonlinear Elasto-plastic material. The bearing capacity that calculated from Terzaghi theory indicates that the failure in the soil mass is due to developing the main stresses level and deformation that leading to occur failure underneath the footing in the soil mass, therefore the behavior of loose sand $\left(D_{r}=40 \%\right)$ at failure is placed between the general shear failure and the failure of local shear [7].

On the other hand, there is a full match between experimental and numerical responses in the reinforced soil with two geogrid layers. Consequently, the finite element model is believed to be extremely credible, as shown in Fig. 10.

The general equation of the soil bearing capacity, according to the theory of Terzaghi [16] in the general shear failure and for the strip footing is as follows:

$\mathbf{q}_{\mathbf{u}}=\mathbf{C N}_{\mathbf{c}}+\mathbf{q} \mathbf{N}_{\mathbf{q}}+0.5 \gamma \mathbf{B} \mathbf{N}_{\gamma}$

In local shear failure:

$q_{\mathrm{u}}=\frac{2}{3} \mathbf{C N}_{\mathrm{c}^{\prime}}+\mathrm{qN}_{\mathbf{q}^{\prime}}+0.5 \gamma B \mathrm{~N}_{\gamma^{\prime}}$

where the internal friction angle gives the following relationship [30]:

$\boldsymbol{\varphi}^{\prime}=\tan ^{-1}\left(\frac{\mathbf{2}}{\mathbf{3}} \tan \varphi\right)$

The general Meyerhoff [35] equation that the depth coefficient $\left(d_{c}, d_{q}, d_{\gamma}\right)$ and the effect of the base shape factor $\left(\mathrm{S}_{\mathrm{C}^{\prime}} \mathrm{S}_{\mathrm{q}^{\prime}} \mathrm{S}_{\mathrm{\gamma}}\right)$ and the inclined load factor $\left(\mathrm{i}_{\mathrm{c}^{\prime}}, \mathrm{i}_{\mathrm{q}}, \mathrm{i}_{\mathrm{\gamma}}\right)$ are considered, is: 

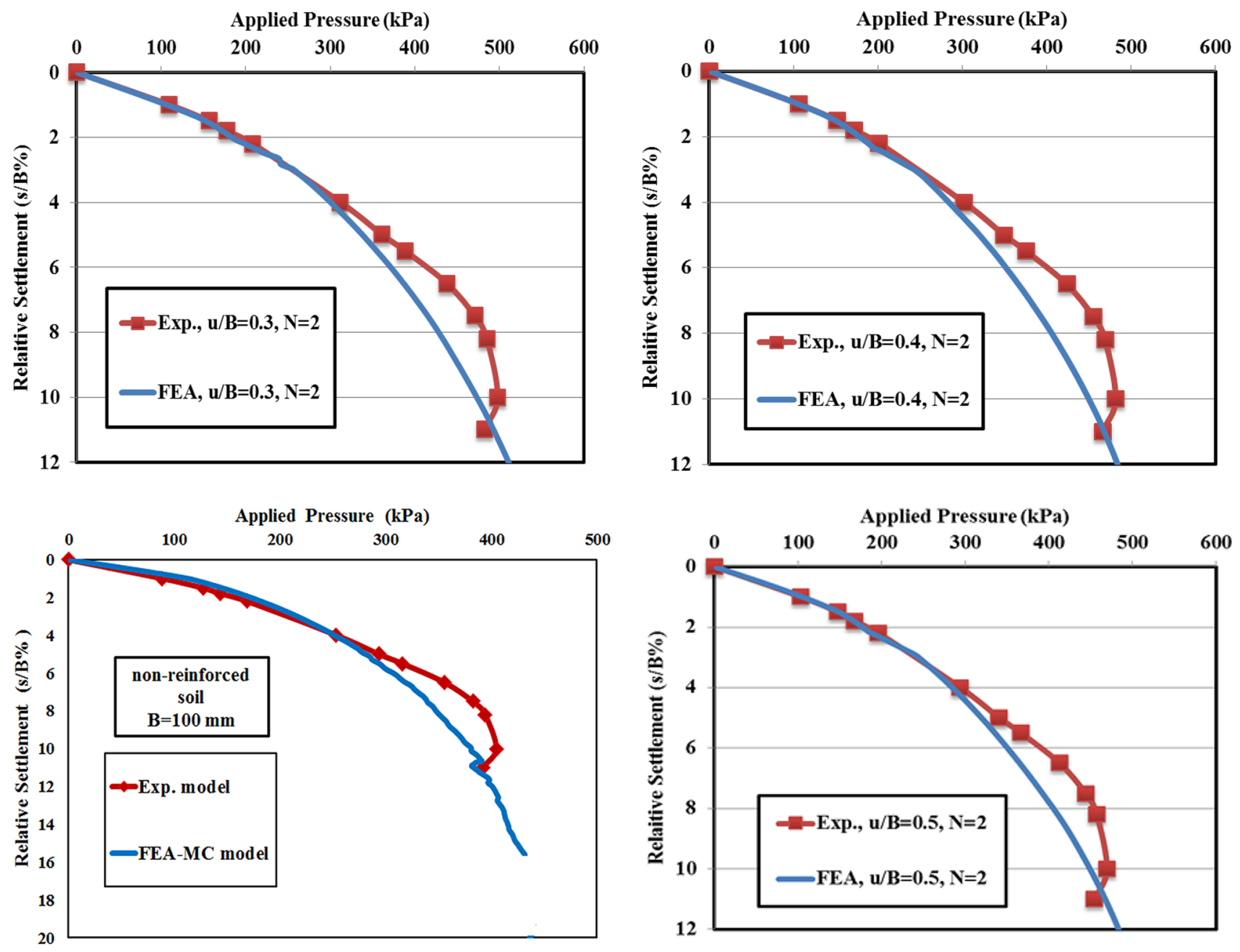

Fig. 10 Calibration the FE-models with a laboratory model in non-reinforced and reinforced soil

$q_{u}=C N_{c} S_{c} d_{c} i_{c}+q N_{q} S_{q} d_{q} i_{q}+0.5 \gamma B N_{\gamma} S_{\gamma} d_{\gamma} i_{\gamma}$

Table 5 Final bearing capacity for numerical, physical and theoretical computations

\begin{tabular}{lcclc}
\hline Method & $\mathrm{Nc}$ & $\mathrm{N} \gamma$ & $\begin{array}{l}\mathrm{q}_{\mathrm{ult}} \\
(\mathrm{kPa})\end{array}$ & $\Delta \mathrm{q}(\%)=\left(\mathrm{q}_{\mathrm{ui}}-\mathrm{q}_{\mathrm{FE}}\right) / \mathrm{q}_{\mathrm{FE}}$ \\
\hline $\begin{array}{l}\text { Terzaghi-General } \\
\quad 316]\end{array}$ & 33.18 & 16.49 & 460.30 & 18.03 \\
$\begin{array}{l}\text { Terzaghi-Local } \\
\quad 16]\end{array}$ & 18.60 & 4.00 & 282.00 & -27.69 \\
$\begin{array}{l}\text { Meyerhof [35] } \\
\text { Hansen [36] }\end{array}$ & 28.59 & 13.99 & 390.70 & 0.18 \\
$\begin{array}{l}\text { Vesic [37] } \\
\text { FEA model }\end{array}$ & 28.59 & 13.54 & 390.36 & 0.09 \\
Physical model & - & 20.30 & 395.42 & 1.39 \\
\hline
\end{tabular}

$$
\begin{aligned}
& \mathbf{N}_{\mathbf{q}}=\mathbf{e}^{\pi \tan ^{2}\left(45+\frac{\phi}{2}\right)} \\
& \mathbf{N}_{\mathbf{c}}=\left(\mathbf{N}_{\mathbf{q}}-\mathbf{1}\right) \cot \boldsymbol{}
\end{aligned}
$$

$\mathbf{N}_{\gamma}=\left(\mathbf{N}_{\mathbf{q}}-1\right) \tan (\mathbf{1 . 4} \phi)$

Hansen [36] developed the Meyerhoff modified to include the base case on sloping soil. Vesic [37] used the Hansen equation with the difference in "the coefficient of the soil's bearing capacity $(\mathrm{N} \gamma)^{\prime \prime}$.

$\mathbf{N}_{\gamma}=\mathbf{2}\left(\mathbf{N}_{\mathbf{q}}+\mathbf{1}\right) \tan (\boldsymbol{\phi}) \quad$ Vesic

$\mathbf{N}_{\gamma}=1.5\left(\mathbf{N}_{\mathbf{q}}-1\right) \tan (\phi) \quad$ Hansen

It is a necessary to compare the numerical test findings with analytical solutions in the case of reinforced soil for 
small-scale model. To validate the reinforced soil case, the same comparison analysis was conducted to achieve the goal. A failure mechanism was presented by Huang and Tatsuoka [38] for a strip foundation holding by reinforcing earth, in which the reinforcement $b$ width is equivalent to the foundation $B$ width [30]. This is known as the deep foundation mechanism in which a quasi-rigid area is created under the foundation. Schlosser [39] suggested an extensive slab mechanism of failure in soil at the ultimate load for the situations where $b>B$. Huang and Meng [40] analyzed the estimation of the final bearing capacity of shallow foundations over geogrid-reinforced sand. In this analysis the extensive slab mechanism is considered. According to this analysis, utilizing Meyerhof's bearing capacity factors, the equation was improved and it is utilized to calculate the $c-\varphi$ soils' bearing capacity [30].

$\mathrm{qur}_{\mathrm{ur}}=\left[0.5-0.1 \frac{B}{L}\right](\mathrm{B}+\Delta \mathrm{B}) \gamma \mathbf{N}_{\gamma}+\gamma d \mathbf{N}_{\mathrm{q}}+\mathbf{C N}_{\mathrm{c}}$

where $L=$ length of the foundation, $\gamma=$ unit weight of soil and

$\Delta \mathbf{B}=2 \mathbf{d} \tan \boldsymbol{\beta}$

The associations for the bearing capacity factors Nc, $N \gamma$ and $N q$ are provided in Meyerhof's Eqs. (11)-(13). The angle $\boldsymbol{\beta}$ is [30]:

$\tan \beta=0.68-2.071\left(\frac{h}{B}\right)+0.743(C R)+0.03\left(\frac{b_{\text {geogrid }}}{B}\right)$

$\mathbf{C R}=\frac{\mathbf{w}}{\mathbf{W}}=\frac{\text { width of reinf orcing strip }}{\text { center to center horizontal spacing of the strips }}$

This Table 6 indicates that it is a decent consistence between the reinforced soil's bearing capacity computed from finite element analysis solutions and theoretical analysis method of Huang and Meng [40]. It is found that the bearing capacity finite element prediction is slightly smaller or larger than Huang and Meng bearing capacity. Different reasons cause to this difference, the most significant of which is that in Huang and Meng equation the soil is assumed as a quasi-rigid earth slab (effect of extensive slab and deep-footing mechanisms) failing suddenly by reaching the soil's bearing capacity. However, in the existing finite element analysis, the soil is assumed as a nonlinear Elasto-Plastic substance deforming by the employed loads, in contrary to a rigid substance which is not deformed. Moreover, the soil can act in a progressive mode owing to the finite element formulation nature, in which the elements can act in a progressive and gradual mode: A yielding material makes an adjacent element yield, until realizing a slip surface. As a result, based on these comparisons between the bearing capacity values of the soil in these three ways (laboratory, numerical and experimental equations) and according to the positive identical results, it can be concluded that the results of numerical analyses in both reinforced and non-reinforced soil circumstances for scale effect study will be good and reliable.

\section{Results and discussions}

Applied pressure-relative settlement curves from the numerical analyses performed on the reinforced and nonreinforced in plain strain circumstances are presented in these discussions for a wide range of the width of strip footings. Two main factors will be defined in this work: Bearing capacity ratio and modulus of Soil reaction. All values for these two coefficients will be calculated according to $s / B=10 \%$. The effect of geogrid reinforcement on the bearing capacity is quantified based on the "Bearing Capacity Ratio (BCR)" [40]. BCR is the ratio of the reinforced soil's final bearing capacity to the final bearing capacity of non-reinforced soil, i.e., $B C R=q_{u r} / q_{u}$.

\subsection{FEA for unreinforced soil at series I}

The final bearing capacity is determined in terms of one of two methods:

- "The tangent technique" where the final bearing capacity "(UBC)" is determined as the pressure equivalent to the intersection of the two tangents (indeed, the final and initial parts of the applied stress-settlement ratio $\left(q_{u}-s / B\right)$ curve) [37].
Table 6 Comparison between the FEA results and analytical solutions in the case of reinforced soil

\begin{tabular}{lllll}
\hline Method & $\mathrm{Nc}$ & $\mathrm{N} \gamma$ & qult (kPa) & $\begin{array}{l}\Delta \mathrm{q}(\%)= \\
\text { (qute-qFE)/qFE }\end{array}$ \\
\hline $\begin{array}{c}\text { Huang and Meng } \\
\text { (Ngeogrid=1) [40] }\end{array}$ & 28.59 & 13.99 & 454 & 0.82 \\
$\begin{array}{c}\text { Huang and Meng } \\
\text { (Ngeogrid=2) [40] }\end{array}$ & 28.59 & 13.99 & 463 & 0.35 \\
FEA (Ngeogrid=1) & - & - & 450 & - \\
FEA (Ngeogrid=2) & - & - & 465 & - \\
\hline
\end{tabular}


- The pressure by the final part of the applied stresssettlement curve $\left(\mathrm{q}_{\mathrm{u}}-\mathrm{s} / \mathrm{B}\right)$ starts to become linear "(the breakpoint method)" [7]. This point represents the relationship between the applied load-settlement curve when it changes to the inflection point where the value of the soil's final bearing capacity is set.

In this work, the final bearing capacity was expressed in terms of the breakpoint method. The loose sandy soil used in this research is of a relative density as $40 \%$. As listed in the literature, granting to the method of assigning the applicable load, the behavior of the loose sand is elastic until the relative settlement reaches to $\mathrm{s} / \mathrm{B}=1 \%$ which corresponds to limit stress equal to $100 \mathrm{kPa}$, as depicted in Fig. 11. Afterward the total settlement rises with the applied load increment and the curve of applied load-the relative settlement is non-linear elastic model until the equal value of $\mathrm{s} / \mathrm{B}=10 \%$ which the breaking point is equivalent to the ultimate failure load. At the breaking point the settlement goes on with a sudden reduction of resistance, and the behavior of loose soil is plastic model. Fig 11 expresses that with increasing width of the footing, the greater the bearing capacity value and the relative settlement is increased. Within the small-scale model, the mechanism of the soil failure beneath footing is close to punching shear failure, but in the large-scale model the failure occurs nearly as a local shear failure. This indicates that the mobilized shear strength relevant to circumstances, in which the footing width is moderately high compared to the equivalent smaller scale tests, especially in the depth of the footing is zero.

Consequently, it resembles occurring two mechanisms: (1) The physical view that progressive failure, defined based on the nonuniform mobilized friction angle and shear strain in the soil at ultimate footing load, is more important since footing width rises; and (2) the

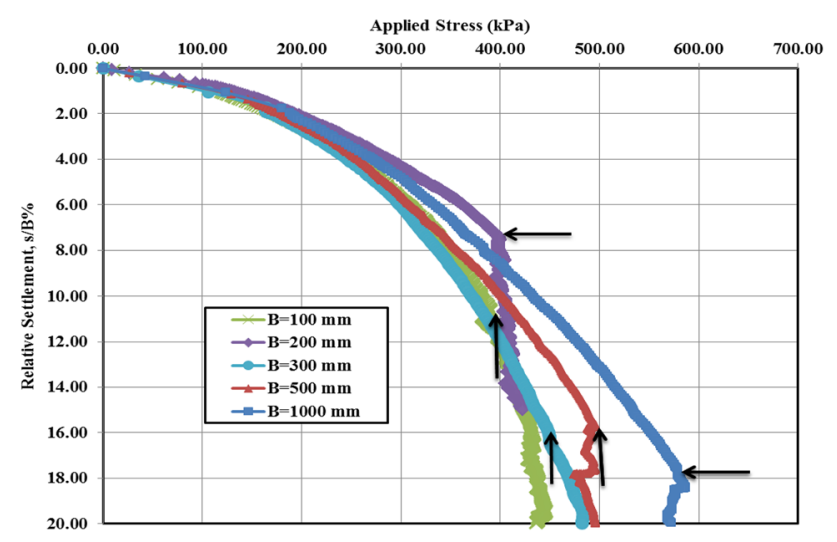

Fig. 11 The unreinforced soil's bearing capacity of footings scale potential for advanced failure, defined by the alteration between the soil's residual and peak strength, is more considerable since the footing width reduces. These effects are investigated by Perkins et al. [41].

\subsection{Finite element analyses of reinforced soil}

Finite element analyses were performed on reinforced and unreinforced fine sandy soil to assess the effect of several elements regarding the carrying out of the strip footing on studying reinforced soils. The components involved in this work include the reinforced area's effective depth, a spacing between reinforcement layers, soil-reinforcement interaction coefficient, reaction modulus of soil reinforcement, optimal top spacing for the two-layer reinforced soil, footing width. For each instance, the load-deformation curve resultant by the finite element simulation, was utilized to adjust the final bearing capacity and relative settlement. The final bearing capacity of the footing was expressed as the bearing capacity corresponding to a settlement ratio (s/B) of $10 \%$ [42].

\subsubsection{The optimal position of the initial reinforcement layer}

To define the best depth of the topmost geogrid layer, some experimental and numerical experiments were performed with a determined depth of the second layer of reinforcement geogrid $(h / B=0.2)$ and by the variation the first layer depth $(\mathrm{u} / \mathrm{B}=$ variable). The following figure indicates the impact of foundation width and reinforcement length on the depth value of the first geogrid layer. It was found that for a wide range of footing widths and the length of the geogrid three times the width of the bases, there is tow ideal depth of reinforcing layer at $u / B=0.33$ and 0.6. The reason for this is ascribable to the mobilized tensile strength and increased apparent cohesion caused by the existence of two layers of reinforcement. That explains the deep footing effect theory. The results of the current work on the optimum $\mathrm{u} / \mathrm{B}$ ratio are consistent with the other investigators $[43,44]$. Shin et al. [43] indicated that for strip footings over geogrid-reinforced sand the final BCR is obtained by $\mathrm{u} / \mathrm{B}$ around 0.3 for reinforced sand. The findings of the experimental model footing tests performed by Abu-Farsakh et al. [44] demonstrated that $\mathrm{u} / \mathrm{B}=0.33$ for geogrid-reinforced silty clay and sand. As for the length of the geogrid is equivalent 5 and 7 of the width of the foundation, the behavior of reinforced soil is a twin for various strips footing width values. In this occurrence, the optimum depth of the uppermost geogrid layer is recognized only in the following value of $0.3 \mathrm{~B}$. This result demonstrates the effect of the wide-slab theory of reinforced soil, as shown in Fig. 12. 


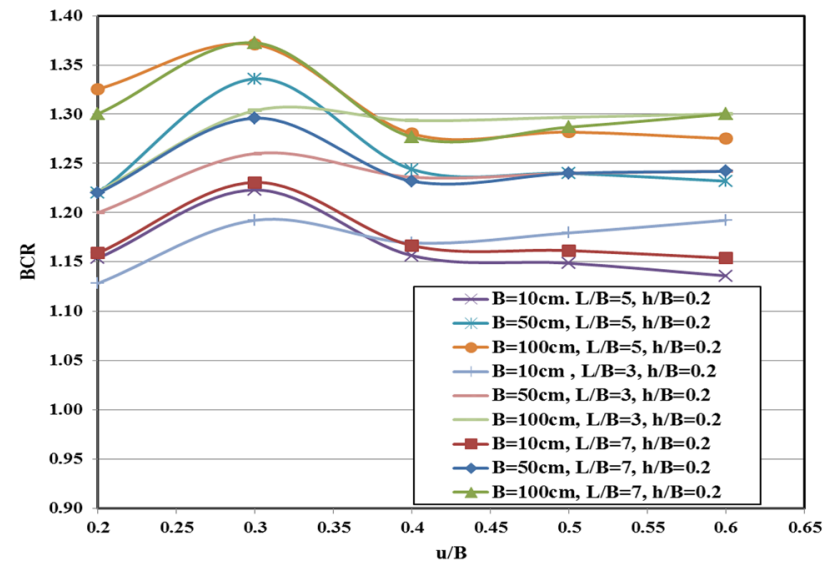

Fig. 12 The value of the $B C R$ with various of uppermost depth ratios $(\mathrm{u} / \mathrm{B})$ and length of reinforcement $(\mathrm{L} / \mathrm{B})$

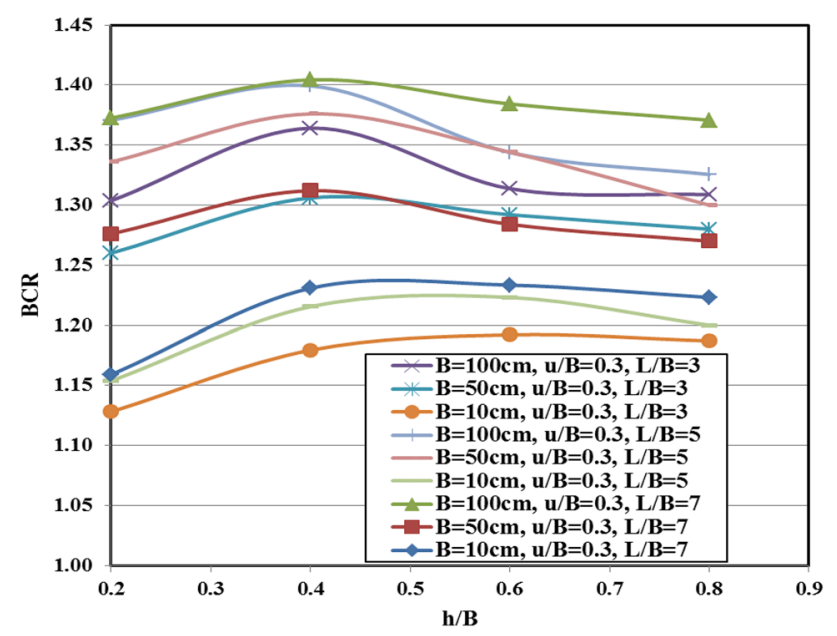

Fig. 13 Effect of reinforcement spacing with various lengths of geogrid (L/B)

\subsubsection{Effect of reinforcement spacing}

The impact of reinforcement spacing ( $h$ ) on the bearing capacity of the footing and the settlement was assessed by altering the space of reinforcement layers into the effective uppermost depth of $0.3 \mathrm{~B}$. Some finite element analyses were performed on the footing-reinforced soil model utilizing a geogrid located at 4 various spacings. At first the $B C R$ rises by increasing the spacing ratio $(h / B)$ and then it reduces followed by a threshold value of $h / B$. This threshold spacing ratio $(\mathrm{h} / \mathrm{B})$ is nearly 0.40 [45-47]. The optimum spacing ratio for 2-layer geogrid is $0.40 \mathrm{~B}(\mathrm{~B}$, the width of footing). This critical ratio leads to hold the greatest effect of the geogrid reinforcement in this character of ground improvement [45]. These consequences are similar with the previous researches in the literature review. The BCR

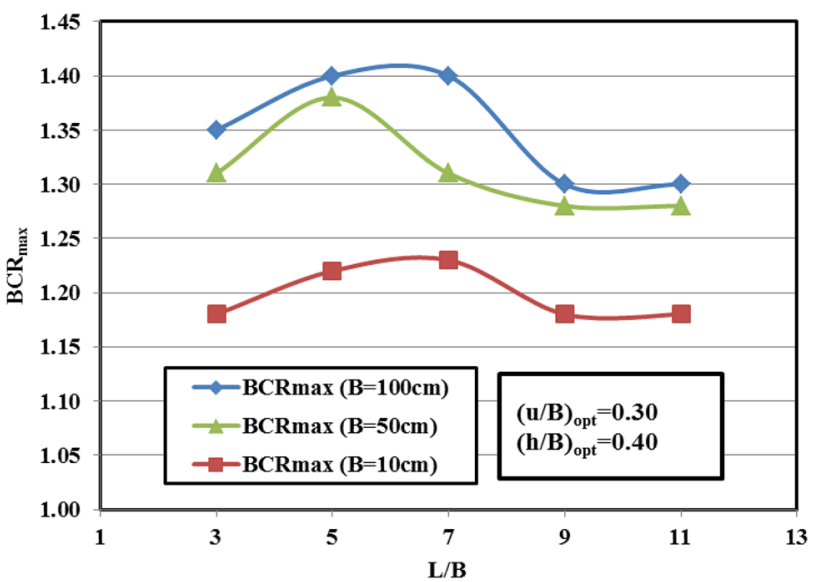

Fig. 14 The value of the $B C R_{\max }$ in various lengths of geogrid

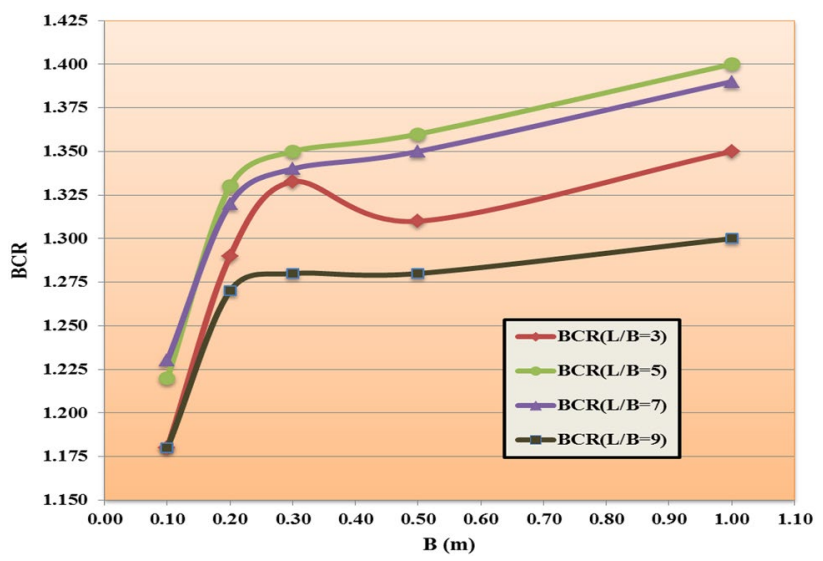

Fig. 15 The change in BCR with footing width as the variable geogrid length

increments by increasing the width footing and length of the geogrid [48]. The percentage difference in the value of the coefficient of improvement between the large and small scale reaches to $25 \%$. Figure 13 indicates that the value of the coefficient of improvement is closer to the footings presented by $0.5 \mathrm{~m}$ and $1.0 \mathrm{~m}$, due to the difference in the level of stresses in the soil under the footing base and the rearrangement of the position of the soil particles in the case of large size of the foundation. As well as the impact of the strength of the reinforcement in the case of the large scale due to the high resistance to the geogrid and the effectiveness of mutual reaction between soil and geogrid.

\subsubsection{Effect of the length of reinforcement}

Some finite element analysis on 2-layer geogrid-reinforced soil was carried out with various reinforcement lengths. The changes of the BCRmax and $B C R$ as a function of the 
reinforcement layers' length and the footing width are presented in Figs. 14 and 15, respectively. Figure 14 displays that the endurance ratio increases by increasing the length of the geogrid layer to an increased threshold value. This increase in the rate of improvement is not linear to the ratio of length to the width of the footing until reaching to the median equal value of 7 , which gives an increase in the amount of endurance ratio to $41 \%, 38 \%$ and $24 \%$ for the base dimensions $1 \mathrm{~m}, 0.5 \mathrm{~m}$ and $0.1 \mathrm{~m}$, respectively. Fig 14 presents for the large scale the increase of the coefficient of maximum improvement by increasing the armament length until the appropriate length ratio is equivalent to 7 times the footing base width. After this value, the coefficient of enhancement gradually decreases to a constant value that is obtained for the reinforcement length equal to 9 times the footing width [9-20,30-52]. This result is similar to the small scale model [48]. Therefore, it is possible to say that in order to obtain high-resistance in the reinforced soil system, it is preferable to use an equal length of geogrid 7 times of the strip footing width that gives the greatest effect of the geogrid reinforcement [48]. The same results that obtained from $[45,46,48]$. Fig 15 illustrates that the higher the footing width, the greater the value of the $B C R$. For a small scale model with a footing widths of 0.1 and 0.2 meters, the BCR is $30 \%$ and $10 \%$ smaller than measured by the large-scale model, respectively. This finding indicates the impact of the scale on the bearing capacity value of the reinforced soil. FEM analysis conducted that the maximum strain along reinforcement happens exactly under the of footing center and reduces by increasing the distance away from the footing center [6]. Therefore, the reinforcement length can also influence on the reinforced soil's performance.

\subsection{The impact of footing width on the reaction modulus of reinforced soil}

The value of subgrade modulus of geogrid-encapsulated soil $\left(k_{\mathrm{sr}}\right)$ is required for soil-structure interaction analysis of structures resting on a reinforced soil, such as footings, pavements, or railroad ties. It is common knowledge that the soil reaction coefficient is computed by the plate load experiments. It is related to the load applied and the settlement of soil beneath footing, resulting from the application of that load on the soil surface. In addition, there are several mathematical equations to calculate the coefficient of unreinforced soil reaction. However, in the case of reinforced soil, there is no mathematical relationship to calculate the coefficient of soil reaction. Since one of the advantages of geogrid is relative rigidity, this property plays an important role in reducing soil settlement under surface foundations. A simple mathematical relationship can be suggested by conducting statistical analysis to calculate the modulus of the geogrid-soil reaction. The modulus of subgrade reaction $\mathrm{k}_{\mathrm{s}}$ is expressed as the uniform pressure per unit settlement utilized to the footing at settlement variations $s / B=10 \%$, as demonstrated below:

$K_{s, r}\left(\frac{k N}{m^{3}}\right)=\frac{q_{r}}{s=0.1 B}$

The variations in the reaction factor of the soil with the influential depth of the geogrid according to the results of laboratory tests series 2 and 3 are illustrated in Figs. 16 and 17, respectively. The magnitude of subgrade modulus increases gradually with decreasing spacing between geogrid layers for all series [47]. And then the greater the spacing between the layers of the geogrid, the lower the value of the soil reaction modulus. Also for the effect of the length of reinforcing, the higher the length of the geogrid, the higher the value of the soil reaction coefficient. Curves in Figs. 16, 17 and 18 also indicate the effect of the scale footings on the reaction coefficient. In Figs. 16 and 17, for the large-scale and small-scale models it is found that the values of reaction coefficient are close to them at the relative length of the geogrid to the footing width is greater or equal to 5 . That means placing the double geogrid layer over the fine-grained sand contains the most effect on the reaction modulus for the ratio of geogrid length to footing width is 5 , but the least effective for $L / B=3[47$, 50]. Consequently, the greatest soil reaction modulus was found in all set of the series, which the optimum values were $u / B=0.3$ and $h / B=0.4$ for relative footing settlement of $10 \%$ [48]. Experimental results in Fig. 19 indicate that increasing the relative settlement leads to decreasing the reaction modulus of reinforced and unreinforced soil. The rate of increased reaction modulus of the reinforced soil in comparison with the unreinforced soil is to 1.26 and 1.12 for two layers and one layer of reinforcing, respectively for all relative settlements. The subgrade reaction modulus is utilized for comparing the findings of finite element analyses and the foreseen values from the analytical solutions for an optimum value of reinforced soil. The subgrade reaction modulus for the geogrid-reinforced sand footing system was calculated in terms of the stated before analytical solutions Huang and Meng [40] from Eq. (20). Figure 18 shows comparing the findings of finite element method (for various footing widths, $B=0.1 \mathrm{~m}$ to $1.0 \mathrm{~m}$ ) and the analytical solutions. As it is observed, the best agreement with the FEA outcomes were found at various lengths of geogrid layer. Terzaghi [49] indicated that it is possible to find $\left(\mathrm{k}_{\mathrm{s}}\right)$, for full-sized footings, from plate load test (PLT) using the following equations. A nonlinear regression model was used to show the reinforced 

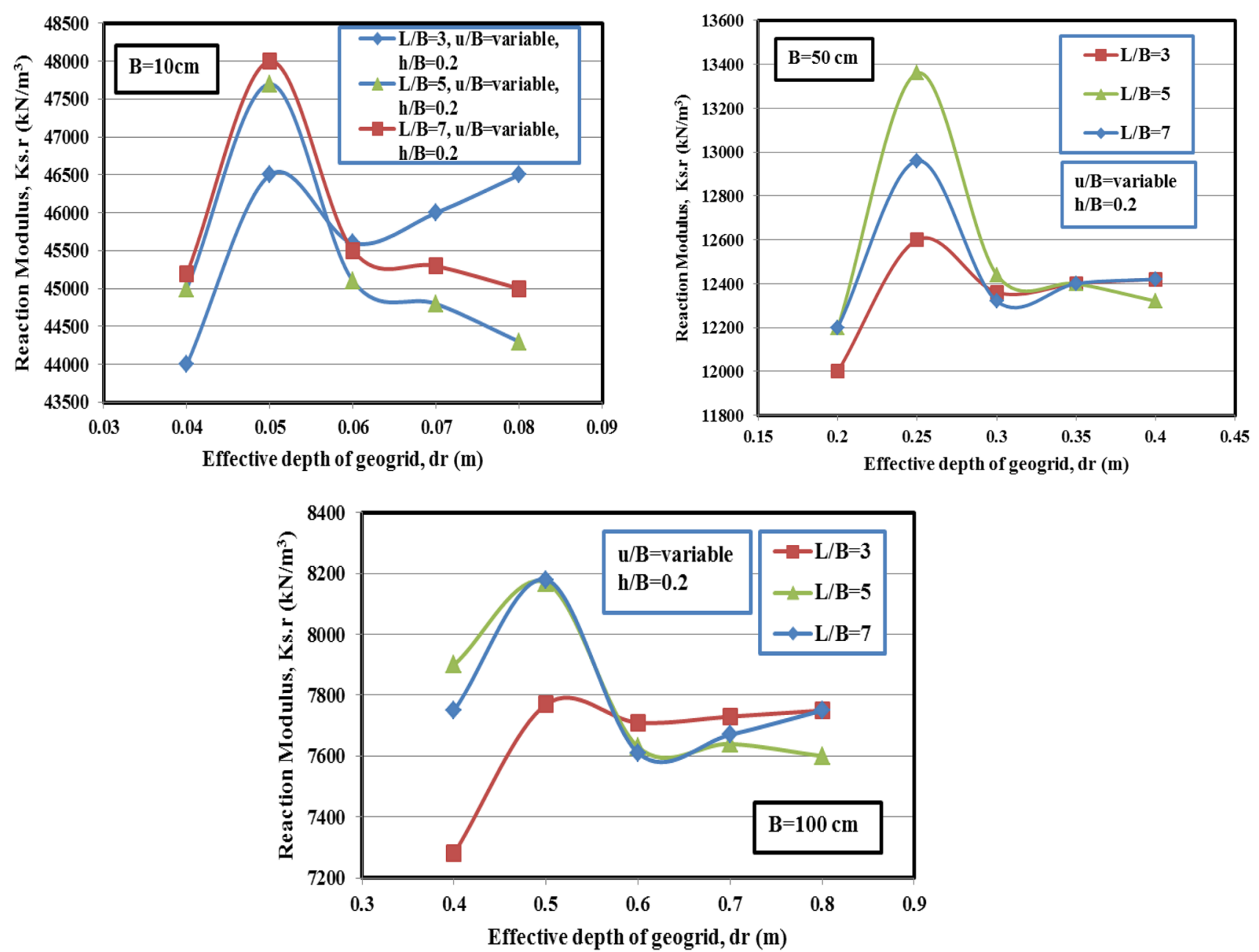

Fig. 16 The variation of $\mathrm{K}_{\mathrm{sr}}$ with an effective depth of geogrid for series II

soil reaction modulus values in an object as it loaded with plain strain conditions. For sandy soils;

$K_{s}=K_{p} \times\left(\frac{B+0.305}{2 B}\right)$

From this FE analysis, Figs. 18, 19, 20 present that based on the optimum values of $(\mathrm{u} / \mathrm{B}),(\mathrm{h} / \mathrm{B})$ and $(\mathrm{L} / \mathrm{B})$ for deriving the maximum benefit to improve the modulus of subgrade reaction of the in geogrid-reinforced soil can be found this general predictive equation from finite element analysis:

$$
\begin{aligned}
& K_{s r}=K_{\text {soil, }(0.305)} \times\left(\frac{B+0.305}{2 B}\right)^{n}=31757 \times\left(\frac{B+0.305}{2 B}\right)^{1.485} \\
& K_{s r}=\frac{q_{u, 0.305}}{0.305} \times \alpha \times\left(\frac{B+0.305}{2 B}\right)^{1.485} \\
& K_{s r}=2 \times K_{\text {soil },(B r e f)} \times\left(\frac{B+0.305}{2 B}\right)^{1.5} ; B_{\text {ref }}=0.305 m
\end{aligned}
$$

The approach used to obtain the above-mentioned equation is as follows. In the beginning, the values of the soil reaction modulus are accounted for an extensive range of footing widths and are extended those values with statistical analysis using numerical analyses data for all series. The outcomes of statistical analysis of the association between the width of the footing $(B)$ and $\mathrm{K}_{\mathrm{sr}}$ indicated that the following power function offers the best fit for the correlation between FEA data $\left(\mathrm{K}_{\mathrm{sr}}\right)$ and footing width (B) (Fig. 19). The subgrade modulus values were also prolonged with present empirical equations (for reinforced soil, provided by Huang and Meng [40]) using the analytical data from $0.10 \mathrm{~m}$ width plate to wide size footings Demir et al. [50]. The outcomes of FEA and empirical equations were compared for determining the correlation a large range of footing width in (Fig. 20). According to the outcomes of the FEA, the modulus of subgrade $\left(\mathrm{k}_{\mathrm{sr}}\right)$ decreases as the width of the plate incremented Fig. 18. However, the values of both methods showed that the findings of the analytical technique are 

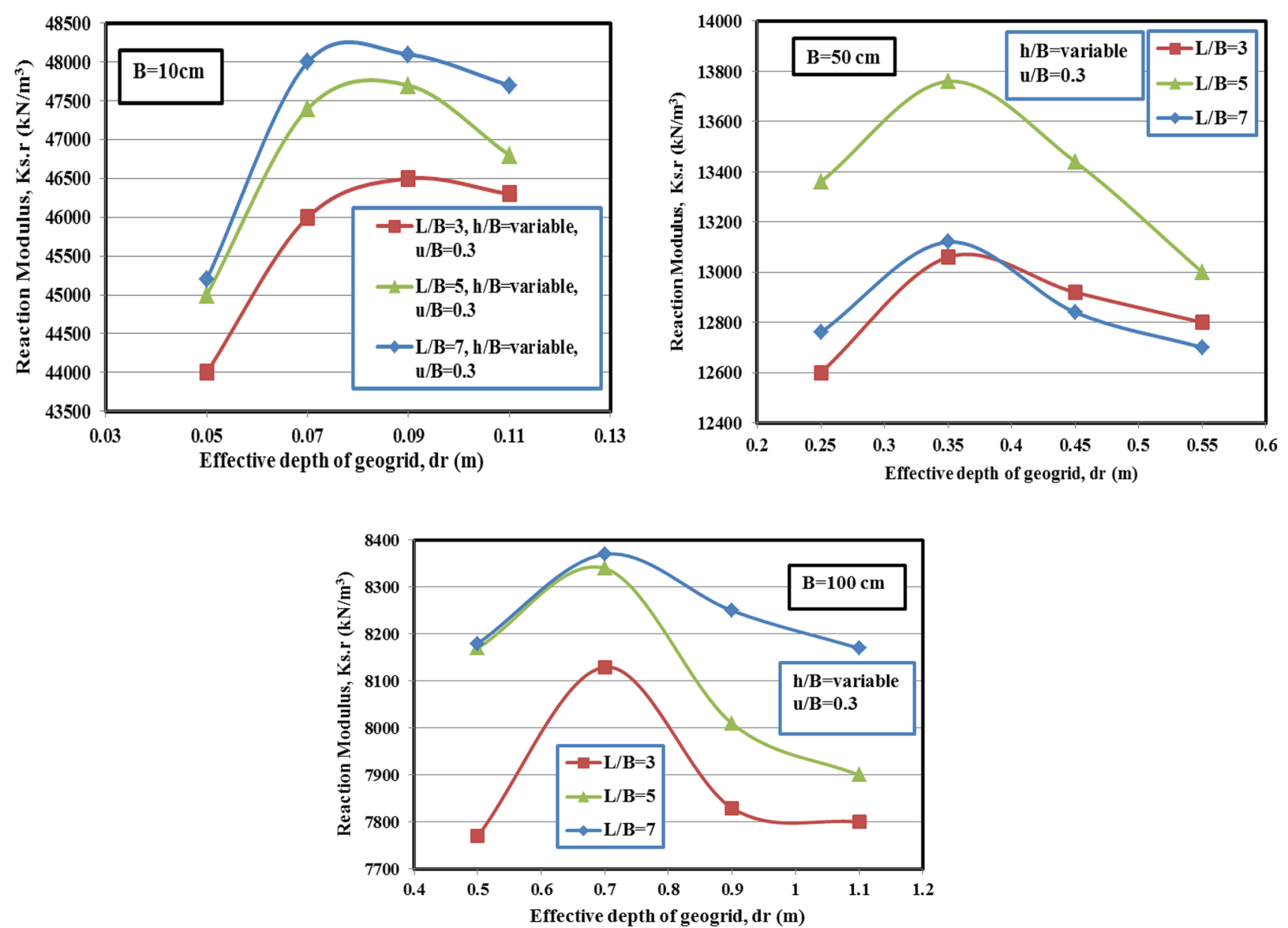

Fig. 17 The variation of $\mathrm{K}_{\mathrm{sr}}$ with an effective depth of geogrid for series III

close to FEA results. It is predicted that the length of the reinforcement element could not affect the values of modulus of subgrade reaction in reinforced soil for the ratio $7<\mathrm{L} / \mathrm{B}<3$, Fig. 20. The same results were reported by DeMerchant et al. [47]. Consequently, it can use an approximate equation (Eq. (23)) to be utilized for strip footing on geogrid-reinforced sandy soil at a medium relative density with this range of the width of the footing $(0.10-1.00) \mathrm{m}$.

\subsection{The impact of effective depth of reinforcement elements on $\mathrm{K}_{\mathrm{SR}}$}

During the past years, several laboratory test results associated with the final and permissible bearing capacities of shallow foundations supported by geogrid-reinforced sand that have been published. The findings indicate that the presence of geogrid as reinforcement helps decrease the settlement of foundations under static loading. Thus, a rational estimate of the reduced elastic settlement of the geogrid-reinforced soil at the surface $\left(D_{f}=0\right)$ can be obtained from relationships such as Eqs. (20) to (23) if a bearing capacity of the soil-geogrid system $\left(q_{r}\right)$ in the zone of stress influence can be obtained. However, it is important to realize that the magnitude of $\left(\mathrm{K}_{\mathrm{SR}}\right)$ of the stabilized soil will be a function of several parameters (Figs. 16, 17) including $[47,50]$ :

(I) Reinforcement stiffness,

(II) Number of geogrid layers in the influence zone (N),

(III) Location of the uppermost layer of geogrid beneath the surface footing $(\mathrm{u} / \mathrm{B})$,

(IV) Length of geogrid layers (L/B),

(V) The distance between geogrid successive layers $(\mathrm{h} / \mathrm{B})$, and

(VI) The effective depth of reinforcement (Dr/B).

Figures 16, 17, 18, 19, 20, 21 illustrate the results of a finite element analysis and plate load test on geogridreinforced soil (tests series II and III). Using Eq. (20), the 

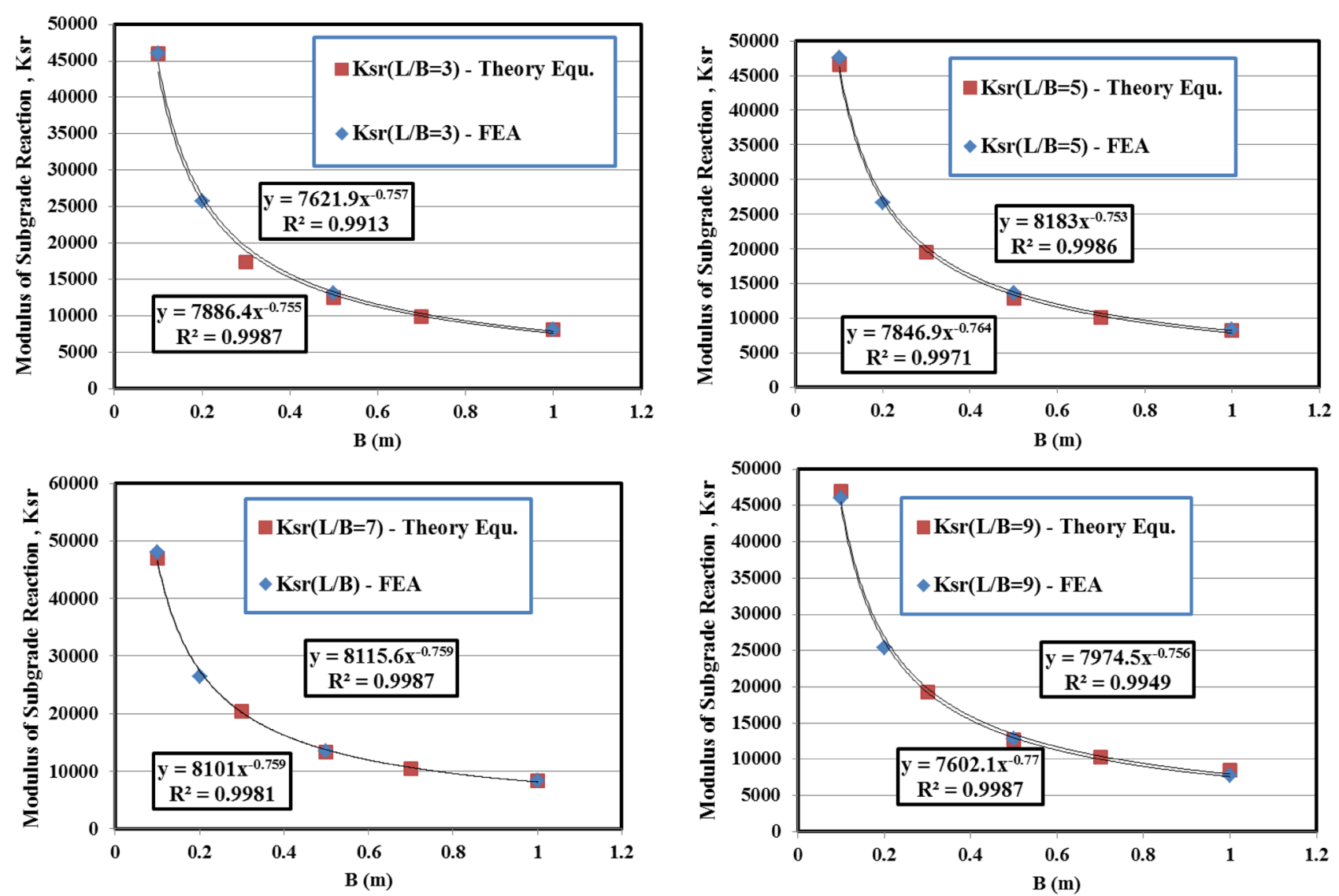

Fig. 18 The variation of $K_{s r}$ with widths of footing at the optimum values of $(u / B=0.3)$ and $(h / B=0.4)$

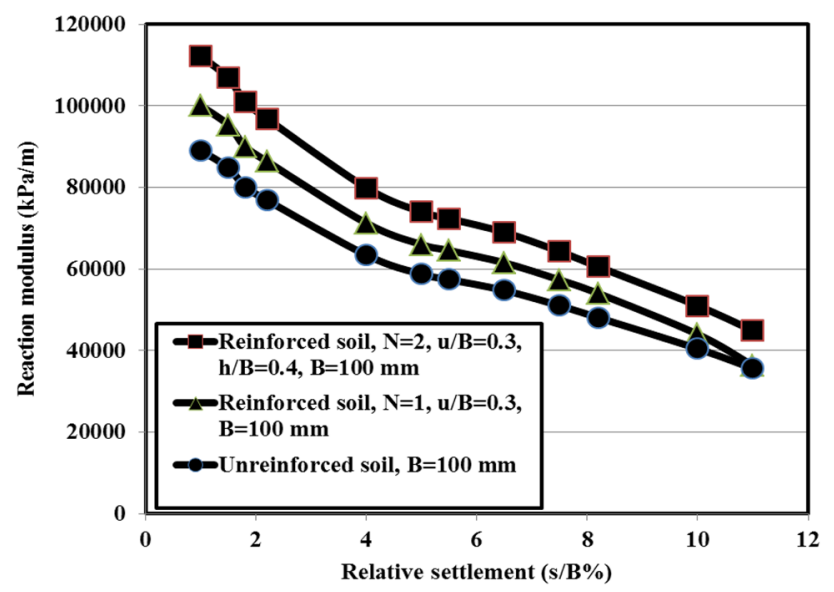

Fig. 19 The relations between the reaction modulus and relative settlement from experimental study

magnitudes of $\mathrm{K}_{\mathrm{SR}}$ were calculated and are presented in Tables 7 and 8. From these tables the following general achievement may be found:

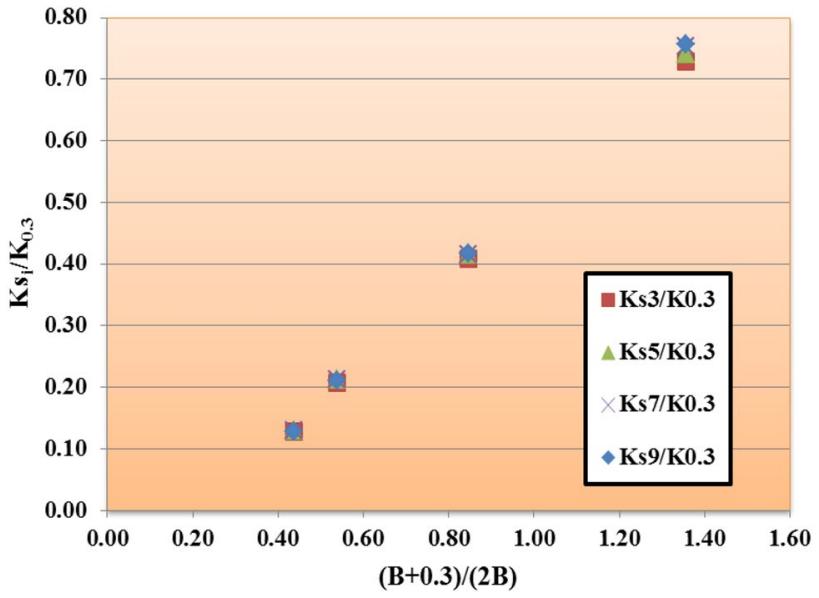

Fig. 20 The variation of relative reaction modulus with a reference footing width

1. Keeping the depth of the uppermost of reinforcement $(\mathrm{u} / \mathrm{B})$ to be constant, the modulus of reaction gradually increases with the spacing between geogrid layers $(\mathrm{h} / \mathrm{B})$ and the length of geogrid layers (L/B) increase. 


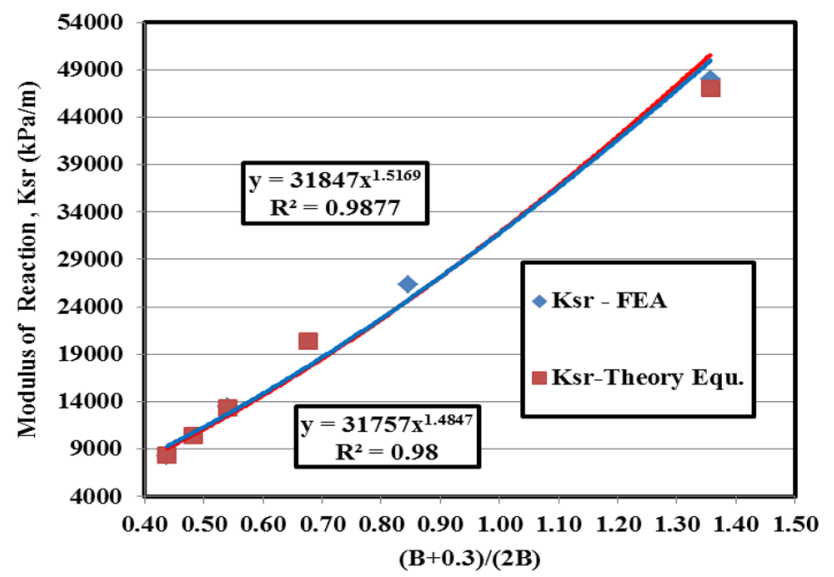

Fig. 21 The variation of reaction modulus with reference width of footing at the optimal values of $(\mathrm{u} / \mathrm{B}),(\mathrm{h} / \mathrm{B})$ and $(\mathrm{L} / \mathrm{B})$

2. Keeping the spacing between geogrid layers ( $h / B$ ) to be constant, the modulus of reaction gradually increases with the depth of the uppermost of reinforcement $(\mathrm{u} / \mathrm{B})$ and the length of geogrid layers $(\mathrm{L} / \mathrm{B})$ increase.

3. It was also observed with the results of the curves of Fig. 20, the length of the geogrid does not affect on the reinforced soil reaction coefficient values with the change of footing dimensions for the reference footing width that is equal to $\mathrm{B}_{f, r e f}=0.305 \mathrm{~m}$.
$K_{S R}=K_{S} \times I_{d r} \times\left(\frac{J_{r}}{E_{s} \times d_{r}}\right)^{m_{r}} ;$ where $: K_{S}=\frac{0.25 \times E_{s}}{B \times\left(1-\vartheta^{2}\right)}$

$I_{d r}:$ Impact coefficient of effective depth of geogrid layer.

$I_{d}=\left(\frac{u}{B}+\frac{h}{B}\right)^{\left(\frac{u}{B}+0.1\right)}$ if $\frac{L}{B}=3$

$I_{d}=\left(\frac{u}{B}+\frac{h}{B}\right)^{\left(\frac{u}{B}+0.22\right)}$ if $\frac{L}{B}=5$

$I_{d}=\left(\frac{u}{B}+\frac{h}{B}\right)^{\left(\frac{u}{B}+0.19\right)}$ if $\frac{L}{B}=7$

$m_{r}$ : Impact coefficient of the length of the geogrid layer.

$\mathrm{K}_{\mathrm{S}}$ : Modulus of subgrade reaction in unreinforced soil for strip footing (Bowles [51]).

Chen et al. [6] proposed that the scale impact is chiefly associated with the reinforced ratio $\left(R_{r}\right)$ of the reinforced region, which is expressed as:

$R_{r}=\frac{E_{R} \times A_{R}}{E_{s} \times A_{s}}$

where $E_{R}$ shows the elastic modulus of the reinforcement $=J / t_{R} ; J$ represents the reinforcement tensile

Table $7 \mathrm{u} / \mathrm{B}=$ constant, $\mathrm{h} / \mathrm{B}=$ variable, $\mathrm{N}=2$ layer, $\mathrm{L} / \mathrm{B}=$ variable

\begin{tabular}{|c|c|c|c|c|c|c|c|c|c|c|c|c|c|}
\hline \multicolumn{12}{|c|}{$B=0.10-0.50-1.00(m)$} & \multicolumn{2}{|c|}{$\begin{array}{l}\text { Test Series } \\
\text { ॥ }\end{array}$} \\
\hline \multicolumn{12}{|l|}{$\mathrm{u} / \mathrm{B}$} & \multirow[b]{3}{*}{$\mathrm{L} / \mathrm{B}$} & \multirow[b]{3}{*}{$h / B$} \\
\hline \multicolumn{2}{|l|}{0.7} & \multicolumn{2}{|l|}{0.6} & \multicolumn{2}{|l|}{0.5} & \multicolumn{2}{|l|}{0.4} & \multicolumn{2}{|l|}{0.3} & \multicolumn{2}{|l|}{0.2} & & \\
\hline Idr & $\mathrm{mr}$ & Idr & $\mathrm{mr}$ & Idr & $\mathrm{mr}$ & Idr & $\mathrm{mr}$ & Idr & $\mathrm{mr}$ & Idr & $\mathrm{mr}$ & & \\
\hline 1.3978 & 0.0384 & 1.4323 & 0.0375 & 1.4224 & 0.0398 & 1.4202 & 0.0426 & 1.4119 & 0.0383 & 1.3121 & 0.0355 & 3 & 0.2 \\
\hline 1.4661 & 0.0501 & 1.4576 & 0.0507 & 1.4453 & 0.048 & 1.4231 & 0.0447 & 1.5362 & 0.0509 & 1.4788 & 0.0593 & 5 & 0.2 \\
\hline 1.4551 & 0.0465 & 1.4818 & 0.0512 & 1.4375 & 0.0446 & 1.3925 & 0.0386 & 1.5077 & 0.04662 & 1.422 & 0.049 & 7 & 0.2 \\
\hline
\end{tabular}

Table $8 \mathrm{~h} / \mathrm{B}=$ constant, $\mathrm{u} / \mathrm{B}=$ variable, $\mathrm{N}=2$ layers, $\mathrm{L} / \mathrm{B}=$ variable

\begin{tabular}{|c|c|c|c|c|c|c|c|c|c|c|c|}
\hline \multicolumn{10}{|c|}{$B=0.10-0.50-1.00(\mathrm{~m})$} & \multirow{2}{*}{\multicolumn{2}{|c|}{$\begin{array}{l}\text { Test Series } \\
\text { III }\end{array}$}} \\
\hline \multicolumn{10}{|l|}{$h / B$} & & \\
\hline \multicolumn{2}{|l|}{0.8} & \multicolumn{2}{|l|}{0.6} & \multicolumn{2}{|l|}{0.5} & \multicolumn{2}{|l|}{0.4} & \multicolumn{2}{|l|}{0.2} & \multirow[b]{2}{*}{$\mathrm{L} / \mathrm{B}$} & \multirow[b]{2}{*}{$u / B$} \\
\hline Idr & $\mathrm{mr}$ & Idr & $\mathrm{mr}$ & Idr & $\mathrm{mr}$ & Idr & $\mathrm{mr}$ & Idr & $\mathrm{mr}$ & & \\
\hline 1.4927 & 0.0435 & 1.4802 & 0.0428 & 1.5288 & 0.0538 & 1.5999 & 0.0637 & 1.5047 & 0.0643 & 3 & 0.3 \\
\hline 1.5287 & 0.0459 & 1.5566 & 0.0475 & 1.6001 & 0.058 & 1.6405 & 0.0624 & 1.6429 & 0.0783 & 5 & 0.3 \\
\hline 1.5798 & 0.0491 & 1.5847 & 0.05 & 1.5987 & 0.0568 & 1.6144 & 0.057 & 1.6023 & 0.0732 & 7 & 0.3 \\
\hline
\end{tabular}


modulus; $A_{R}$ denotes for the area of reinforcement per unit width $=N t_{R} \times 1 ; t_{R}$ shows the reinforcement thickness; $N$ represents the number of reinforcement layers; $E_{s}$ shows the soil's elasticity modulus; $A_{s}$ is the area of reinforced soil per unit width $=d_{r} \times 1 ; d_{r}$ is the overall depth of reinforced zone $=u+(N-1) h$.

Reinforcement stiffness is a key parameter affecting the reinforced soil foundation's performance. The reinforcement stiffness was normalized as follows [50-52].

$E_{\text {normal }}=\frac{J_{r}}{E_{s} \times d_{r}}$

where $E_{\text {normal }}$ is the normalized stiffness of reinforcement.

\subsection{An approach to determine subgrade reaction modulus}

A simple new method is proposed to precisely set the subgrade reaction coefficient for reinforced sandy soil. This method is based on the characteristics and features of the applied load-settlement curves. Since the behavior of the reinforced soil is nonlinear inelastic so that the settlement increases gradually with the increase of the applied load, the coefficient of the reinforced soil reaction is calculated as follows:

1. The following amount $\left(s / q_{r}\right)$ is calculated by dividing the amount of settlement by the amount of the applied load so that the inverted soil reaction coefficient is obtained.
2. The previous amount is drawn against the settlement resulting from the applied load, this is a linear curve that expresses the relationship between the inverted soil reaction coefficient and the settlement.

3. The plot $\left(s / q_{r}\right)$ versus $s$ gives a straight line where ' $a$ ' is the intercept on the Y-axis and ' $b$ ' is the slope of the line as shown in Fig. 22.

4. The linear bond between the inverted coefficient of the reaction and the settlement can be expressed according to the following linear equation:

$\frac{s}{q_{r}}=a+b \times s O r, s=\frac{a \times q_{r}}{1-b \times q_{r}}$

The reciprocal of $(1 / b)$ represents the maximum load stress applied on the reinforced soil, which is larger than ultimate bearing capacity at failure. Differentiation of Eq. (27) concerning settlement gives the inverse of $(1 / a)$ as the initial reaction modulus $\left(\mathrm{K}_{0}\right)$.

5. The modulus of subgrade reaction $\left(\mathrm{K}_{\mathrm{s}}\right)$ has been calculated from the relevant applied stress-settlement curve at the stress level of $q_{u}$. The settlement at $q_{u}$ is $s_{u}$ :

$s_{u}=\frac{a \times q_{u}}{1-b \times q_{u}}$

Therefore, the reaction modulus of reinforced soil is divided the ultimate applied stress on the ultimate settlement,

$K_{s r}=\frac{q_{r u}}{s_{u}}=\frac{1-\left(b \times q_{u}\right)}{a}$

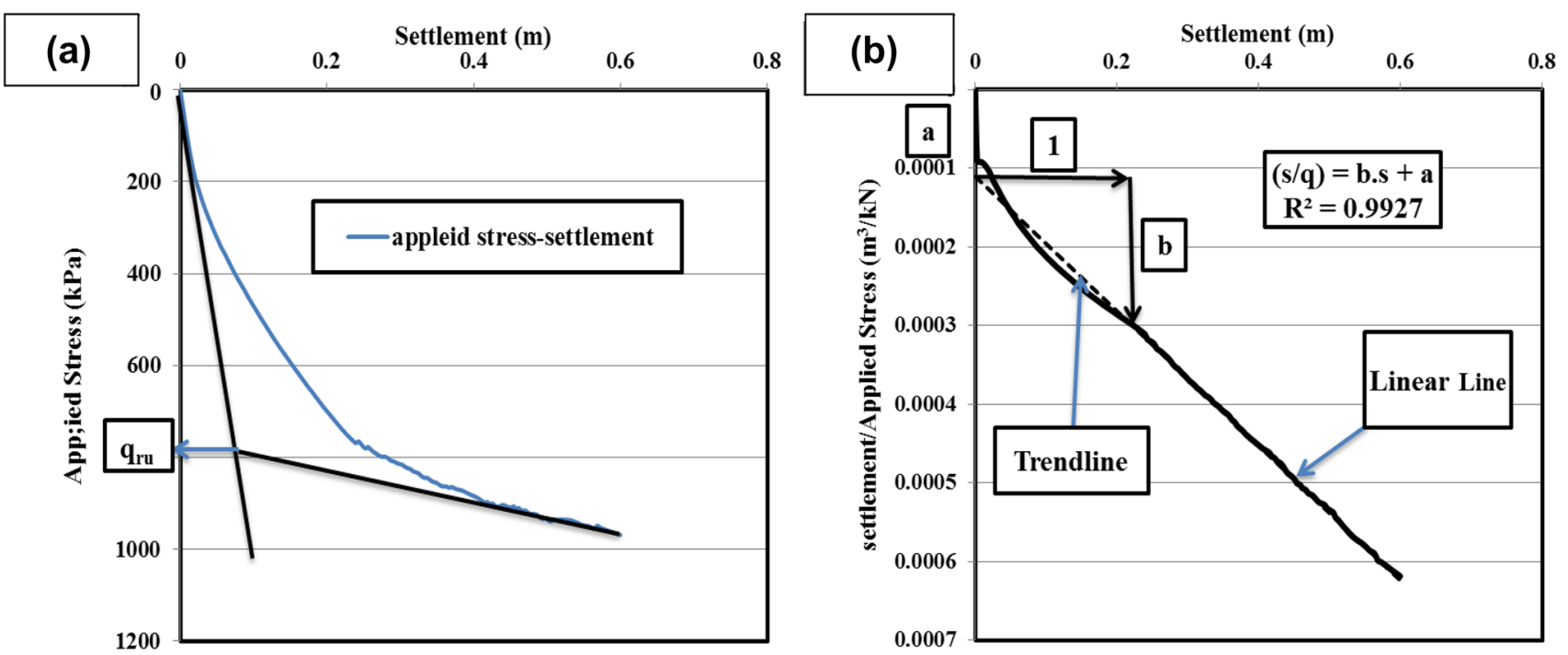

Fig. 22 a Typical experimental test data. b Transformed applied stress-settlement curve 
Table 9 The comparison between experimental and numerical results

\begin{tabular}{|c|c|c|c|c|c|c|c|c|c|}
\hline \multirow{2}{*}{$\begin{array}{l}\mathrm{B}=100 \mathrm{~m} \\
\text { Parameters }\end{array}$} & \multicolumn{4}{|l|}{ Exp. results } & \multicolumn{4}{|l|}{ FE-results } & \multirow[b]{2}{*}{ Error \% } \\
\hline & $a\left(m^{3} / k N\right)$ & $\mathrm{b}\left(\mathrm{m}^{3} / \mathrm{kN}\right.$ & $\mathrm{q}_{\mathrm{ur}}(\mathrm{kPa})$ & $\mathrm{K}_{\mathrm{sr}}(\mathrm{kN} / \mathrm{m} 3)$ & $a\left(\mathrm{~m}^{3} / \mathrm{kN}\right.$ & $\mathrm{b}\left(\mathrm{m}^{3} / \mathrm{kN}\right.$ & $\mathrm{q}_{\mathrm{ur}}(\mathrm{kPa})$ & $\mathrm{K}_{\mathrm{sr}}(\mathrm{kN} / \mathrm{m} 3)$ & \\
\hline Unreinforced soil & $7.00 \mathrm{E}-06$ & 0.0018 & 405 & $3.87 E+04$ & $7.00 \mathrm{E}-06$ & 0.0019 & 392 & $3.65 E+04$ & 5.83 \\
\hline Reinforced soil $(\mathrm{N}=1)$ & $6.00 \mathrm{E}-06$ & 0.0017 & 450 & $3.92 \mathrm{E}+04$ & $6.00 \mathrm{E}-06$ & 0.0018 & 430 & $3.77 \mathrm{E}+04$ & 3.83 \\
\hline Reinforced soil $(\mathrm{N}=2)$ & $7.00 \mathrm{E}-06$ & 0.0015 & 504 & $3.49 E+04$ & $7.00 \mathrm{E}-06$ & 0.0016 & 485 & $3.20 E+04$ & 8.20 \\
\hline
\end{tabular}

To validate this novelty method, it should be compared with the results from experimental and numerical analysis from this current study for a small-scale model. The summary of comparison results was shown in Table 9. This table indicates that the majority factor that affects the results is related to the maximum applied load (b). As a result, the modulus of reaction in an experimental study is different from the numerical outcomes. This difference is due to the curvature of the progressive settlements under applied stress between laboratory and numerical studies. On the other hand, the initial reaction modulus is not much effect on both the results of experimental and finite element models. The maximum error is less than ten percent. Therefore, it can be calculated the exact value of the reaction modulus of reinforced soil by applying the stress-settlement curve of either experimental or numerical analysis.

\section{Conclusions}

The experimental and numerical investigations were conducted on strip footing resting on the geogrid reinforced fine sand layer. At the beginning, an evaluation of the significance of geogrid reinforcement to enhance the soil's strength is demanded to take out a series of a small-scale model of reinforced and unreinforced soil beneath static loading. Succeeding, the series of the large-scale numerical analyses were implemented to define the soil bed reaction modulus and bearing capacity ratio of reinforced sand soil in plane strain conditions. The Mohr-Coulomb soil constitutive model was employed to represent the fine sandy soil and the linear elastic tension model was utilized for modeled geogrid reinforcement elements. According to the results of finite element analyses of a strip footing resting on the reinforced fine sand by using a range of widths of the footing, it is concluded that:

1. The effective length of reinforcement layers for full mobilization in reinforced fine-grained sand is to be equal to $5.0 \mathrm{~B}$, where $\mathrm{B}$ is the footing width. Where it was found that the tensile strength distribution diagram of the reinforcing element is maximum at the length of the geogrid equal to $2 \mathrm{~B}$ and then gradually decreases to reach zero at $3 \mathrm{~B}$.

2. The optimum location of the top reinforcement layer is about $0.3 \mathrm{~B}$ for the two-layer reinforcement system. And the optimum spacing between geogrid layers finds to be $0.4 \mathrm{~B}$ for the same system. In practice, the impact of geogrid turns into trivial when the ratio of the depth of the uppermost layer to the footing width is greater than 0.65 and the spacing between geogrid layers is $0.75 \mathrm{~B}$.

3. The inclusion of geogrid layers as reinforcement leads to increase the overall stiffness, ultimate bearing capacity and the modulus of the reaction of the subgrade reinforcement. The increase in the soil reaction modulus is due to the decrease in the settlement because of the addition of geogrid into the soil.

4. The results of the numerical investigation proved that the coefficient of soil reaction is associated in a non-linear relationship with the relative stiffness of the reinforced soil. For the multi-layer of geogrid, the reaction coefficient of reinforced soil will need to be studied in future research.

5. The impact of the geogrid length on the reinforced soil reaction coefficient values with changing the ranges of footing width can be neglected and $\mathrm{K}_{\mathrm{SR}}$ is related only to the effective depth of reinforcement. The value of subgrade modulus increases when the spacing between geogrid layers is less than 0.45 and the optimum depth of inclusion geogrid within the soil is $(u / B=0.3$ and $h / B=0.4)$.

6. In the strip foundations, the footing widths affect the bearing capacity ratio and the modulus reaction. The modulus reaction decreases when the footing width is increased. The increase in the settlement is due to the increase in the applied load (width of the footing), therefor the value of the reaction coefficient decreases.

7. The association between the foundation width and the bearing capacity in reinforced soil is almost non-linear, for the range of testing foundations widths. The same behavior for the reinforced soil reaction modulus $\left(\mathrm{K}_{\mathrm{SR}}\right)$ is true.

8. This study proposes a new simple method to determine the subgrade modulus of geogrid reinforced soils. This method is based on the characteristics of 
the applied pressure-settlement curves. It can be used this new approach for a wide range of reinforced soil and for any type of geosynthetic material.

\section{Compliance with ethical standards}

Conflict of interest The authors approve no known conflicts of interest related to this work and no considerable financial support influencing its results.

\section{References}

1. De Beer E (1965) The scale effect in the transposition of the results of deep-sounding tests on the ultimate bearing capacity of pile sand caisson foundations. Geotechnique 13(1):39-75

2. Tatsuoka F, Okahara M, Tanaka T, Tani K, Morimoto T, Siddiquee MSA (1991) Progressive failure and particle size effect in bearing capacity of a footing on sand. Geotech Eng Cong ASCE 2:788-802

3. Das BM, Omar MT (1994) The effects of foundation width on model tests for the bearing capacity of sand with geogrid reinforcement. Geotech Geol Eng Tech Note 12:133-141

4. Cerato $A B$, Lutenegger $A J$ (2007) Scale effects of shallow foundation bearing capacity on granular material. J Geotech Geoenviron Eng ASCE 133(10):1192-1202

5. Kumar A, Ohri ML, Bansal RK (2007) Bearing capacity tests of strip footings on reinforced layered soil. Geotech Geol Eng 25(2):139-150

6. Chen Q (2007) An experimental study on characteristics and behavior of reinforced soil foundation. Ph.D. Dissertation, Louisiana State University

7. Mosallanezhad M, Alfaro MC, Hataf N, Taghavi SH (2016) Performance of the new reinforcement system in the increase of shear strength of typical geogrid interface with soil. Geotext Geomembr 44(3):457-462

8. Tavakoli Mehrjardi Gh, Khazaei M (2017) Scale effect on the behaviour of geogrid-reinforced soil under repeated loads. Geotext Geomembr 45:603-615

9. Abu El-Soud S, Belal AM (2018) Bearing capacity of rigid shallow footing on geogrid-reinforced fine sand-experimental modeling. Arab J Geosci 11:247. https://doi.org/10.1007/s1251 7-018-3597-0

10. Lee KL, Seed HB (1967) Drained strength characteristics of sands. J Soil Mech Found Div 93(SM6):117-141

11. Bolton MD, Lau CK (1989) Scale effects in the bearing capacity of granular soils. In: Proceedings of the 12th International Conference Soils Mechanics and Foundation Engineering, vol 2. Balkema Publishers, Rotterdam, pp 895-898

12. Toyosawa T, Itoh K, Kikkawa N, Yang J, Liu F (2013) Influence of model footing diameter and embedded depth on particle size effect in centrifugal bearing capacity tests. Soils Found 53(2):349-356. https://doi.org/10.1016/j.sandf.2012.11.027

13. Kusakabe O (1995) Chapter 6: Foundations. In: Taylor RN (ed) Geotechnical centrifuge technology. Blackie Academic Professional Ed, London, pp 118-167

14. Fakher A, Jones C (1996) Discussion on Bearing capacity of rectangular footings on geogrid-reinforced sand by Yetimoglu T, Wu JTH, Saglamer A, (1994). J Geotech Geoenviron Eng ASCE 122:326-327
15. Zhu F, Clark JI, Phillips R (2001) Scale effect of strip and circular footings resting on dense sand. J Geotech Geoenviron Eng ASCE 127(7):613-621

16. Terzaghi K (1943) Theoretical soil mechanics. Wiley, NewYork

17. Bowles JE (1996) Foundation analysis and design (fifth edition). McGraw-Hill, London, pp 219-270: 501-588

18. Selvadurai APS (1979) Elastic analysis of soil-foundation interaction. Elsevier, New York

19. Brinkgreve RBJ, Broere W, Waterman D (2004) Plaxis-finite element code for soil and rock analysis. Version 8.2 Plaxis BV, The Netherlands

20. Alamshahi S, Hataf N (2009) Bearing capacity of strip footings on sand slopes reinforced with geogrid and grid-anchor. Geotext Geomembr 27:217-226

21. Aria S, Shukla SK, Mohyeddin A (2017) Optimum burial depth of geosynthetic reinforcement within sand bed based on numerical investigation. Int J Geotech Eng. https://doi. org/10.1080/9386362.2017.1404202

22. Boushehrian JH, Hataf N (2003) Experimental and numerical investigation of the bearing capacity of model circular and ring footings on reinforced sand. Geotext Geomembr 23(2):144-173

23. Basudhar PK, Saha S, Deb K (2007) Circular footings resting on geotextile-reinforced sand bed. Geotext Geomembr 25(6):377-384

24. El Sawwaf MA (2007) Behavior of strip footing on geogridreinforced sand over a soft clay slope. Geotext Geomembr 25(1):50-60

25. Chao SJ (2006) Study of geosynthetic reinforced subgrade expressway in Taiwan. In: Fourth international conference on soft soil engineering (4th ICSSE), Vancouver, Canada, pp 237-243

26. Zidan A (2012) Numerical study of behavior of circular footing on geogrid-reinforced sand under static and dynamic loading. Geotech Geol Eng 30:499-510

27. Yu Y, Damians IP, Bathurst RJ (2015) Influence of choice of FLAC and PLAXIS interface models on reinforced soil-structure interactions. Comput Geotech 65:164-174

28. Infante DJU, Martinez GMA, Arrua PA, Eberhardt M (2016) Shear strength behavior of different geosynthetic reinforced soil structure from direct shear test. Int J Geosynth Ground Eng. https://doi.org/10.1007/s40891-016-0058-2

29. Athanasopoulos GA (1993) Effect of particle size on the mechanical behaviour of sand-geotextile composites. Geotext Geomembr 12(3):255-273

30. Das BM (2014) Advanced soil mechanics, principles of geotechnical engineering, 4th edn. CRC Press, Boca Raton

31. Kolbsuzewski J (1948) General investigation of the fundamental factors controlling loose packing of sands. In: Proceedings of the 2nd International Conference on Soil Mechanics and Foundation Engineering, vol 4. Rotterdam, pp 47-49

32. Plaxis (2002) User Manual. 2D version8.2 (Edited by Brinkgreve RJB) Delft Univ Techn and PLAXIS, The Netherlands

33. Abu-Farsakh M, Chen Q, Sharma R (2013) An experimental evaluation of the behavior of footings on geosynthetic-reinforced sand. Soils Found 53(2):335-348

34. Viswanadham BVS, König D (2004) Studies on scaling and instrumentation of a geogrid. Geotext Geomembr 22:307-328

35. Meyerhof G (1951) The utimate bearing capacity of foundation. Geotechnique 2(4):301-311

36. Hansen JB (1970) A revised and extended formula for bearing capacity. Danish Geotech Instit Bul (28), Copenhagen

37. Vesic AS (1973) Analysis of ultimate loads of shallow foundations. J Soil Mech Found Div ASCE 99 (SMI):45-73 
38. Huang C, Tatsuoka F, Sato Y (1994) Failure mechanisms of reinforced sand slopes loaded with a footing. Soils Found 24(2):27-40

39. Schlosser F, Jacobsen HM, Juran I (1983) Soil reinforcementgeneral report. In: Proc VIII Euro Conf Soils Mech Found Eng Helsinki Balkema 83

40. Huang CC, Menq FY (1997) Deep-footing and wide-slab effects in reinforced sandy ground. J Geotech Geoenviron Eng ASCE 123(1):30-36

41. Perkins S, Madson C (2000) Bearing capacity of shallow foundations on sand: A relative density approach. J Geotech Geoenviron Eng ASCE 126(6):521-530

42. Yoo C (2001) Laboratory investigation of bearing capacity behavior of strip footing on a geogrid-reinforced sand slope. Geotext Geomembr 19(5):279-298

43. Shin EC, Das BM, Lee ES, Atalar C (2002) Bearing capacity of strip foundation on geogrid-reinforced sand. Geotech Geol Eng 20:169-180

44. Abu-Farsakh M, Chen Q, Yoon S (2007) Use of Reinforced Soil Foundation (RSF) to Support Shallow Foundation. Rep No FHWA/LA.04/423 Louisiana Transp Res Cent Baton Rouge LA 195

45. Cicek E, Guler E, Yetimoglu T (2015) Effect of reinforcement length for different geosynthetic reinforcements on strip footing on sand soil. Soils Found 55(4):661-677

46. El Sawwaf M, Nazir AK (2010) Behavior of repeatedly loaded rectangular footings resting on reinforced sand. Alex Eng J 49(4):349-356. https://doi.org/10.1016/j.Egg.2010.07.002
47. DeMerchant MR, Valsangkar AJ, Schriver AB (2002) Plate load tests on geogrid reinforced expanded shale lightweight aggregate. Geotext Geomembr 20:173-190

48. Abu El-Soud S, Belal AM (2019) Numerical modeling of rigid strip shallow foundations overlaying geosythetics-reinforced loose fine sand deposits. Arab J Geosci. https://doi.org/10.1007/s1251 7-019-4436-7

49. Terzaghi K (1955) Evaluation of coefficient of subgrade reaction. Geotechnique 5(4):297-326

50. Demir A, Laman M, Yildiz A, Ornek M (2013) Large scale field tests on geogrid-reinforced granular fill underlain by clay soil. Geotext Geomembr. https://doi.org/10.1016/j.geote xmem.2012.05.007

51. Bowles JE (1996) foundation analysis and design, 5th edn. The McGraw-Hill Companies, New York

52. Chen Q, Abu-Farsakh M, Sharma R (2009) Experimental and analytical studies of reinforced crushed lime stone. Geotext Geomembr 27(5):357-367

Publisher's Note Springer Nature remains neutral with regard to jurisdictional claims in published maps and institutional affiliations. 